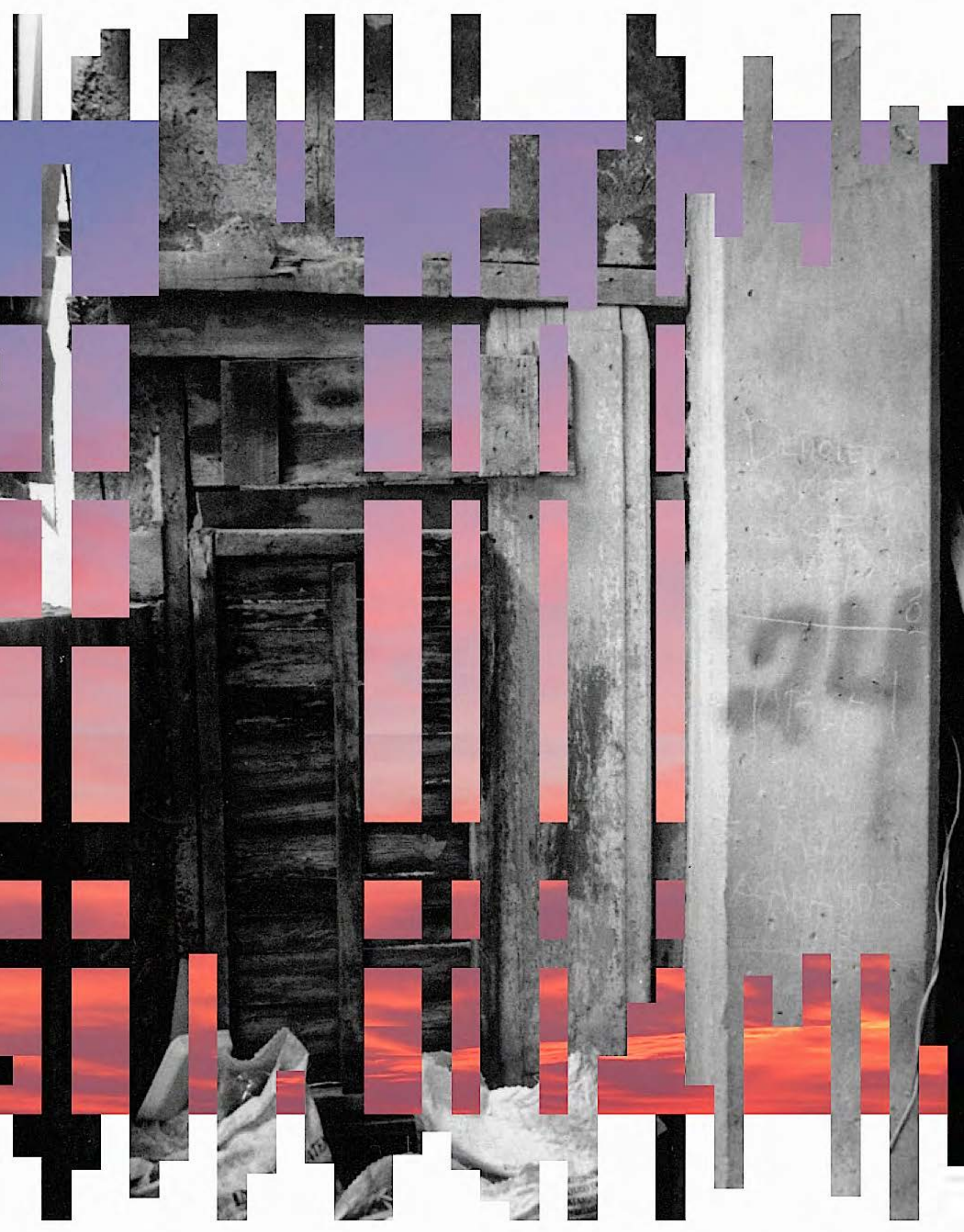




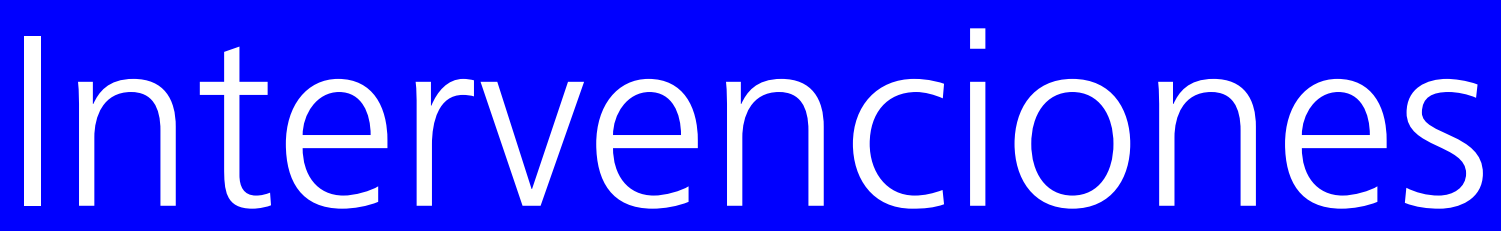

urbanas y tejido

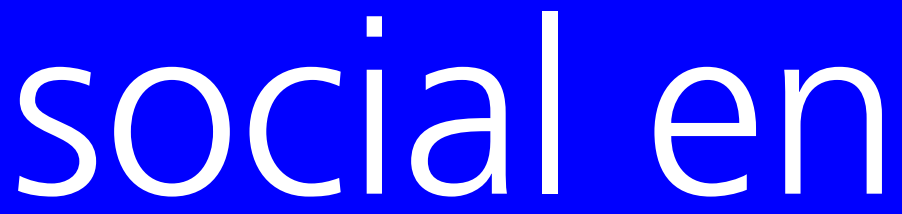

la Ciudad

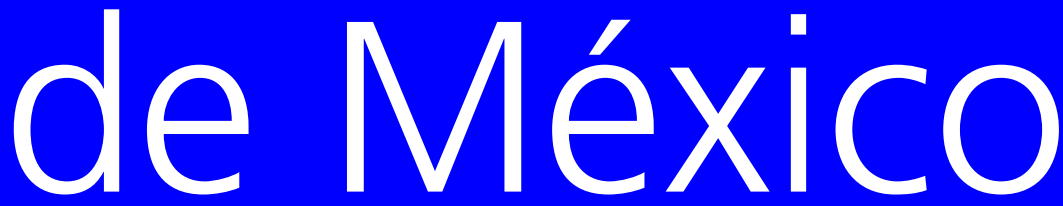

Beatriz Itzel Cruz Megchun

Cruz Megchun, Beatriz Itzel. (2017). La aplicación de intervenciones urbanas como medio para consolidar el tejido social en una zona marginal 


\section{Intervenciones urbanas y tejido social en la Ciudad de México}

\section{Beatriz Itzel Cruz Megchun}

Doctora en Gestión de Diseño, Maestra en Gestión de Diseño y Licenciada en Diseño Industrial. Profesora asistente en Gestion del diseño American University of Sharjah (United Arab Emirates). bcruzmegchun@aus.edu

Fecha de recepción: 01 de agosto, 2016

Enviado a corrección: 20 de septiembre, 2016

Fecha de aceptación: 30 de enero, 2017

\section{Resumen}

Esta investigación explora el uso de intervenciones urbanas como un medio para fortalecer el tejido social en una zona marginal de la Ciudad de México. Al mismo, trata de entender la taxonomía de las intervenciones junto con sus operaciones para revelar la posible participación del diseño. Un caso de estudio longitudinal fue utilizado para discutir la evolución de las intervenciones urbanas y la participación ciudadana en un área geográfica específica. Durante la recolección de datos se documentaron mejoras en el tejido social de la comunidad. Los resultados exhibieron tres diferentes tipos de intervenciones y colaboraciones permitiendo transformaciones sociales y desarrollo cultural.

Palabras clave | intervenciones urbanas; comunidad; identidad; tejido social; prácticalugar; diseño 
INTERVENCIONES URBANAS Y TEJIDO SOCIAL

EN LA CIUDAD DE MÉXICO

\begin{abstract}
This research explores the use of urban interventions to strengthen the social fabric in a marginal area of Mexico City. It also aims to understand taxonomy of the interventions along with the its operations to reveal the possible participation of design. A longitudinal case study was used to discuss the evolution of urban interventions and citizen participation in a geographic area. During the data collection, improvements were documented in the social fabric of the community. The results showed three different types of interventions and collaborations enabling social transformation and development of cultural innovations.
\end{abstract}

Keywords | urban interventions; community; identity; social fabric; practice-place; design 
INTERVENCIONES URBANAS Y TEJIDO SOCIAL

EN LA CIUDAD DE MÉXICO

\section{Introducción}

En los años recientes, la comunidad científica junto con organismos gubernamentales (nacionales e internacionales), han creado plataformas para abordar el desafío que plantea el crecimiento sostenido de las ciudades. En diversos foros (The Global Urban Summit, World Cities Summit, Urban Transitions, CityLab, entre otros) se han discutido los retos a los cuales se enfrenta la población global: la urbanización, la pobreza, el envejecimiento y el crecimiento exponencial de la población urbana. De acuerdo con World Urban Forum (2006), se espera que para el 2030 la población mundial ascenderá a cinco billones de personas, de las cuales dos billones vivirán en condiciones de pobreza, residiendo en asentamientos marginales e informales, que los excluye de oportunidades ofrecidas por la ciudad. Esto nos lleva a abordar temas de la ciudad como sus políticas, su diseño, sus procesos, su historia, su contexto y cómo estos factores interdependientes pueden llevar a obtener equidad y riqueza para sus habitantes bajo la realidad actual.

Aravena (2006) plantea que, si la ciudad es vista como una fuente de equidad, las políticas estarán dirigidas a mejorar la calidad de vida de los más pobres, provocando la disminución de niveles de segregación, violencia y resentimiento de la población. Esto coadyuvará a generar condiciones para la creación de instrumentos, medios y espacios que retengan el conocimiento producido en esas locaciones. Este conocimiento generará riqueza que será redistribuida, formando así, un circulo virtuoso. El reto es encontrar opciones alineadas, contextualizadas y viables que aseguren el bienestar social de los ciudadanos. Así que, se deberán considerar un conjunto de factores ambientales, económicos, políticos, sociales, y de sanidad, incluido el comportamiento humano.

La falta de reconocimiento de las necesidades de los ciudadanos puede orillar al fracaso de programas gubernamentales; también puede provocar que los ciudadanos tomen una serie de acuerdos (formales o informales) mediante consensos para desarrollar proyectos participativos que respondan a sus intereses.

Discutir acerca de la ciudad, e incluso definirla, es una tarea ardua ya que hay varios factores que la encapsulan, además de valores sociales y acciones, que son tan abstractos que fallan 
INTERVENCIONES URBANAS Y TEJIDO SOCIAL

EN LA CIUDAD DE MÉXICO

en reflejar su realidad. Por ejemplo, los griegos tenían la noción del concepto polis referente no solo a la política, sino al hombre, que en sí es una creatura política. Por ello se encuentra adecuado por naturaleza a vivir donde la comunidad en su conjunto hace la ciudad. Después de la época helenista (romana), la ciudad concebida como urbs prevaleció sobre civitas, es decir era un lugar justo donde la gente se reunía, afirmando con ello la idea de comunidad.

Durante el siglo veinte, la ciudad fue reorientada alrededor de los medios privados, como automóviles. Incluso otros actores formales e informales empezaron a tomar los espacios públicos y aceras orillando con ello a los ciudadanos a cercar los espacios públicos y de convivencia social. Bajo este contexto, los espacios cívicos comunes fueron despreciados y degradados. Por ello, el interés de este trabajo radica en entender a la ciudad como un ente vivo, que no solo representa un lugar con edificios y personas, sino que considera las siguientes premisas: es un asentamiento que tiene una densidad poblacional, un sistema urbano con una jerarquía, una circunscripción física (material) o mental (simbólica), que establece un perímetro legal donde se aplican restricciones y privilegios, un registro escrito y leyes que gobiernan a la comunidad y establecen fuentes de propiedad, un favorecimiento en la fuente de ingresos, una relación próxima con la zona rural para el intercambio de servicios y productos, y una distinción a través de definiciones monumentales. Así mismo, la ciudad ofrece un espacio donde coexisten diferentes grupos étnicos, razas y religiones, los cuales tienen la opción a diferentes trabajos especializados. Por ello, la riqueza no está distribuida equitativamente entre los ciudadanos.

De acuerdo con Kostof:

(...) las ciudades son amalgamas de edificios y personas. Son entornos habitados donde rituales diarios -mundanos y extraordinarios, aleatorios y sistematizados- derivan su validez. Son un artefacto urbano y sus mutaciones son condesadas en continuidades de tiempo y lugar. La ciudad es el máximo recuerdo de nuestras luchas y glorias: es donde se exhibe el orgullo del pasado y se pone en exhibición $(1991,26)$. 
INTERVENCIONES URBANAS Y TEJIDO SOCIAL

EN LA CIUDAD DE MÉXICO

Bajo ese entendimiento, las ciudades reflejan en su ambiente urbano la diversidad de los grupos sociales que la conforman. Las personas transforman las ciudades y sus ambientes urbanos, a través de sus actividades generando con ello un significado. Sin embargo, la súper modernidad de las ciudades empuja a los lugares, espacios y sus ritmos a segundo plano (Augé, 1995); esto lleva a producir no-lugares, refiriéndose a aquellos espacios que son asignados a posiciones específicas y circunscritas, que designan dos complementarias pero distintas realidades. La primera, los espacios son formados en relación con ciertos fines (transporte, tránsito, comercio o diversión) y la segunda, es la relación que individuos tienen con esos espacios, ambos son importantes en la generación de memorias. Lo interesante de estos espacios es que comparten ciertos rasgos que permiten llevar prácticas de manera temporal por un tiempo determinado. Así mismo, se convierten en espacios alternativos que son más naturales, menos impuestos, y auto-regulados por los ciudadanos.

Este trabajo ${ }^{1}$ explora una serie de proyectos participativos en una zona marginal, para luego discutir la posible aportación del diseño como un instrumento de cambio y transformación en zonas marginales. La hipótesis es que el diseño actúa como un medio en la adquisición de conocimientos y su subsecuente transformación en esfuerzos sociales traducidos en programas culturales, educativos, sociales y/o recreativos que beneficien a la comunidad. Se documentó un caso de estudio longitudinal en la Unidad Habitacional CTM Culhuacán, Sección 7, Zona 8-11, en la Ciudad de México, donde un grupo de vecinos intervinieron varios espacios en dicha locación para llevar a cabo prácticas artísticas, culturales y sociales que les permitieron fortalecer el tejido social. Estas prácticas fueron realizadas en lugares específicos, marcándolos de manera intrínseca en la memoria colectiva de las personas que transitan y viven en esas áreas. Estos rituales urbanos se convirtieron en un instrumento discursivo para transformar un grupo de personas en signos visibles.

1 La autora agradece el apoyo, la experiencia y el tiempo dados por el Sr. Joel Cruz Cruz, sin los cuales este trabajo no hubiera sido posible. 
La estructura de este documento se divide en cinco secciones, que permitirán entender las intervenciones llevadas a cabo en el caso de estudio. La primera sección elabora el marco teórico del caso, donde se definen los conceptos de lugar, espacio, práctica, ritual y comunidad. Después, se enfocará en examinar la actividad del diseño como agente de conocimiento e instrumento discursivo en intervenciones urbanas. La segunda sección describe la perspectiva filosófica, los métodos de investigación, los procedimientos y el marco de estudio (escenario). La tercera sección describe las intervenciones como un caso de estudio longitudinal para continuar con la cuarta sección que es la discusión de los resultados obtenidos. La quinta sección provee conclusiones y recursos necesarios para divisar futuras acciones.

\section{Lugar-Espacio}

Los conceptos de lugar y espacio han sido investigados y adoptados por diferentes disciplinas académicas como la antropología, la geografía (humana), la filosofía, entre otras. En la antropología, el término espacio es más abstracto en sí mismo que el término lugar, ya que su uso se refiere a un evento (que ha tomado lugar), un mito (que se dice que ha tomado lugar) o una historia (posiciones de autoridad). Michel de Certeau (1990) describe el lugar como un ensamble de elementos coexistentes en un cierto orden y al espacio como una animación de estos lugares por la moción de cuerpos en movimiento. En la geografía humanista, espacio y lugar son conceptos importantes. Entrikin (1991) divide el lugar en dos dimensiones, la parte objetiva que denota sus cualidades naturalistas mientras que la subjetiva abarca significados individualistas vinculados al lugar, básicamente a nivel representacional. Así mismo, introduce el concepto lugares intermedios que es el punto de encuentro para el espacio subjetivo y objetivo, son lugares donde el significado y la realidad objetiva se encuentran. Relph (1976), quien es un geógrafo, trata de mantener la relación entre lugar y espacio y no presentarlos como conceptos separados. Para él, la cualidad del lugar es que tiene el poder de ordenar y enfocar espacialmente las intenciones, experiencias y acciones humanas (Seamon \& Sowers, 2008). 
INTERVENCIONES URBANAS Y TEJIDO SOCIAL

EN LA CIUDAD DE MÉXICO

Consecuentemente, espacio y lugar se estructuran dialécticamente en la experiencia humana, ya que la compresión del espacio está relacionada con los lugares que habitamos y que derivan por ello del significado del mismo. En filosofía, Tuan (1977) estudió no solo el lugar y espacio, sino que también el ambiente. El espacio es descrito como una locación que no tiene conexiones para los seres humanos, ya que no se le ha atribuido ningún valor por ser un espacio abierto. El lugar es más que una locación ya que es creado a través de experiencias humanas. Este existe en el espacio que es llenado de significados y objetivos de experiencias humanas; por ello, el tamaño de su ubicación no importa porque es ilimitado. De ahí deriva un área en dos diferentes formas: la primera es directa e íntima, a través de los sentidos como la visión, olor, tacto y audición; mientras que la segunda es indirecta y conceptual mediada por símbolos, como el arte (Tuan, 1977, 6). De igual forma, Lefebvre (1991) y Soja (1996) consideraron un tercer término que es un espacio entendido como un paisaje físico y social que está impregnado con significado de las prácticas sociales cotidianas y emerge a través de los procesos que operan sobre escalas espaciales y temporales variables. Hay tres escalas que pueden ser distinguidas. El espacio percibido, que incluye tanto las burbujas emocionales de comportamiento que rodean invisiblemente a las personas, así como las complejas organizaciones espaciales de práctica que dan forma al espacio de las acciones. El espacio concebido, se refiere a nuestro conocimiento del espacio que es producido primariamente por discursos de poder e ideología y el cual es construido por profesionales. El espacio, que es el espacio donde todos los espacios son y donde la subjetividad y la objetividad, lo abstracto y lo concreto, se encuentran. Estas últimas ideas de un tercer concepto enfatizan la intermediación del lugar, a través de unir algo que no puede ser separado. Similarmente, Jauhiainen (2005) ha dividido el estudio de espacios urbanos en cuatro extensas categorías. Espacio como materialidad, es donde el espacio existe como un producto de una actividad económica. Espacio como un carácter distintivo, es donde el espacio parece como consistente de fronteras, la especialidad de la locación se estresa. Espacio como una actividad se enfoca en la relación socio-espacial en el espacio. El espacio como contextualizado, el espacio solo existe después de haber dado un sentido a través de la conciencia humana, así como por los medios de los recursos materiales. 
INTERVENCIONES URBANAS Y TEJIDO SOCIAL

EN LA CIUDAD DE MÉXICO

Para los propósitos de esta investigación, el espacio es algo abstracto, sin ningún significado substancial. Lugar, se refiere a cómo las personas están conscientes de o son atraidas a un cierto pedazo de espacio. Consecuentemente, el lugar es un espacio que está socialmente construido y operando, incluyendo la interacción entre personas, usos institucionales del suelo, decisiones políticas y económicas, y el lenguaje de la representación (Saar \& Palang, 2009). Por ello, discutiremos dos conceptos de cómo se utiliza el lugar-espacio por la sociedad: post-it city (La Varra, 2003) y terrain vague (Solá-Morales, 1996). En opinión de La Varra (2003), los lugares son complejos y heterogéneos porque son temporales, no-codificados, e intensifican los espacios en donde diversos grupos de la sociedad llevan a cabo diferentes, múltiples y aceptables códigos de comportamiento. Los rasgos que caracterizan a estos lugares están relacionados con las prácticas llevadas dentro de un espacio urbano regulado o inmerso con ellos; la naturaleza temporal de la actividad (capacidad de no dejar rastros); y el tiempo determinado en que se llevan a cabo las prácticas (los objetos implicados desaparecen después de un intervalo de tiempo). Solá-Morales (1996) considera los espacios como lugares que son reincorporados dentro de la lógica productiva a través de la transformación de espacios reconstruidos que tienen valor en la ruina y en su falta de productividad. Estos espacios urbanos son lugares donde la sociedad puede manifestarse a través de ámbitos alternativos de libertad para alcanzar una realidad lucrativa. En ambos casos el comportamiento y la cognición ocurre de manera conjunta y al mismo tiempo, ya que toda percepción requiere una acción y cada acción requiere una percepción.

\section{Práctica-Fabricación significado}

Un lugar antropológico es formado por identidades individuales, a través de lenguajes específicos, referencias locales y de reglas no formuladas del saber vivir. Su complejidad se basa en que la propia conceptualización de las personas cambia constantemente haciendo que las nociones de espacio y lugar resulten abstractas, difusas e imprecisas (Casey, 1996; Ingold, 2008; Hirsch, 1995; Hubbard, et al, 2004; Massey, 2005). Sin embargo, las intervenciones que ocurren, lugar-práctica-espacio, ilustran como las mentes trabajan conjuntamente en la sociedad y como sus operaciones son estructuradas por acuerdos sociales. 
INTERVENCIONES URBANAS Y TEJIDO SOCIAL

EN LA CIUDAD DE MÉXICO

De acuerdo con Durkheim (1997) y Halbwachs (1950), la conformación de grupos es esencial para recordar eventos particulares y generar material para una memoria colectiva. Lo que los individuos recuerdan es determinado por su pertenencia a un grupo y su propia percepción acerca de una práctica. Esta es concebida como una colección de actividades que pueden establecerse como una forma tácita de conocimiento, una actividad humana y su realización (Lee \& Ingold, 2006; Sheringham, 2006). Esto es el resultado del nexo total de acciones y actividades humanas interconectadas como el conocimiento, significado, ciencia, poder, lenguaje, instituciones sociales, y transformaciones históricas (Schatzki, 2001).

Las prácticas son esenciales porque caracterizan a las personas, como el significado caracteriza el lugar y su identidad. Las identidades de las personas son creadas a través de la definición de sí mismos con relación al lugar (Jorgensen \& Stedman, 2001). El dar una identidad y generar un significado, son procesos que toman un patrón complejo, consciente o inconsciente de ideas, creencias, preferencias, memorias, sentimientos, valores, metas y tendencias de comportamientos y habilidades que son relevantes para este ambiente (Vorkinn \& Riese, 2001). Devine-Wright y Lyons (1997) afirman que cuanto más activos e involucrados estén los individuos en actividades tradicionales, más fuerte será el vínculo entre el individuo y el lugar. Otro carácter limitante que influye en la identidad de las personas es la cultura. Esta involucra procesos de socialización común que toma lugar a través del compartir experiencias, signos y símbolos similares (Low, 1994; Hirsch \& O’Hanlon, 1995). De acuerdo con Pink, "viviendo la vida y realizando intervenciones no se separan de qué y quiénes somos - son procesos del que somos parte de" $(2012,25)$. Es decir, las prácticas son fundamentales para entender la sociedad de la que formamos parte porque no son actos individuales o dislocados de un contexto mayor, sino un reflejo de nuestra identidad. Todas aquellas prácticas que tienen una secuencia de actividades que involucran gestos, palabras y objetos y que son realizados en un lugar, trasmiten un sentido de ritual (Aractingi \& Le Pape, 2011). Estos rituales tienen un formalismo, tradicionalismo, invariancia, reglas, simbolismos (sacros) y funcionamiento (Bell, 1997). Por supuesto, no hay que confundirla con la formación comunitaria, porque ésta usa varias narraciones como las históricas o culturales, e incluso físicas, naturales y experimentales, para crear una relación con el signi- 
INTERVENCIONES URBANAS Y TEJIDO SOCIAL

EN LA CIUDAD DE MÉXICO

ficado del lugar. Martin (2003) las ha llamado marcos de lugares ya que están en constante transición y son rehechas para crear un terreno común para la acción colectiva y dar forma a las ideas de las personas sobre el lugar. Es por eso que nuevos significados son creados para traer experiencias, intereses y valores comunes.

\section{Comunidad y memoria}

Una comunidad no solo es un grupo de personas que comparten elementos en común, como valores, tareas, visiones del mundo, o que tienen una ubicación geográfica, situación social o rol específico, entre otros; sino que es un medio para crear una identidad común que es compartida y elaborada entre sus integrantes. Las comunidades pueden ser examinadas desde el contexto de una locación donde existen múltiples tradiciones culturales y sociales. Paasi (2001) ha señalado que el carácter conexo de los significados personales y colectivos en el día de hoy es más diversificado por que las personas tienen antecedentes regionales e historias personales de identificación haciendo que las comunidades sean más diversas. Por supuesto, las personas usan sus identidades formadas anteriormente en diferentes localidades para adherir significado a nuevos lugares. Por ende, es importante entender cómo las personas comparten y conectan tanto en la vida real como en las comunidades virtuales, ya que en la última década ha habido un fenómeno emergente de formación de comunidades de abajo hacia arriba, iniciativas cívicas vecinales y arreglos regionales. Para los propósitos de esta investigación, todo miembro que comparte intereses, comportamientos, actitudes, percepciones o sentimientos acerca de una necesidad o un objetivo en común para coadyuvar a su mejora.

El uso contemporáneo del término memoria colectiva puede ser rastreado hasta el siglo XIX. Durkheim (1997) y Halbwachs (1950) estudiaban la memoria como un medio que permitiera a un grupo de personas generar material para seleccionar eventos dependiendo de los intereses que perseguían. Esto es posible a través del entendimiento de cómo las mentes trabajan juntas y funcionan a través de arreglos sociales. Lo que los individuos recuerden es determinado por su participación en el grupo y su percepción de ese momento en un espa- 
INTERVENCIONES URBANAS Y TEJIDO SOCIAL

EN LA CIUDAD DE MÉXICO

cio. De acuerdo con Halbwaschs (1950, 2), cada aspecto, cada detalle, de un lugar tiene un significado intangible que es entendido solo por los miembros del grupo, es decir por cada porción de su espacio corresponden diferentes y diversos aspectos de las estructuras y vida de su sociedad. Por ejemplo, los migrantes tienden a conformar grupos para cristalizar las memorias individuales en memorias colectivas que les permitan recordar su lugar de origen en nuevos entornos físicos. Académicos han tratado de explicar el aumento de interés en el pasado, conmemoración, nostalgia e historia en contextos que van desde promociones para el consumidor, cultura popular, diseño de interiores y exteriores, y hasta espacios públicos. La memoria colectiva nos influencia a través de la comunicación diaria integrada en la forma de una cultura objetivada, a través de textos, imágenes, ritos, edificios, monumentos, ciudades e incluso paisajes. Los gobernantes están desarrollando estrategias para conectar a los ciudadanos y a las ciudades con su pasado histórico y simbólico, con el fin de generar un significado emocional y/o soluciones funcionales para el desarrollo futuro.

\section{Cohesión social e intervenciones}

En los últimas tres décadas América Latina ha registrado avances en materia económica, social e institucional. Sin embargo, sigue arrastrando problemáticas que necesita encarar, como: altos índices de pobreza e indigencia, desigualdad, discriminación y exclusión social. Es importante entender que la mejora de estos tres factores son una condición básica para avanzar a sociedades más igualitarias, justas e incluyentes, lo que no garantiza per se su logro. Es esencial que de manera simultánea se consideren las características y calidad de ese crecimiento, junto con el marco de derechos en el que se encuentra inmerso y el tipo de vínculos y relaciones sociales que lo moldean. La idea de cohesión social surge como un acto de reflexión que se opone a la acentuación de las brechas sociales, al surgimiento de identidades autorreferidas, la excesiva racionalización económica y la tendencia a la individualización y al debilitamiento público (Ottone, 2007, 13). Su acepción es múltiple, posiblemente porque esta puede variar dependiendo de las sociedades, regiones, en las que está aplicada. Otro problema al que se enfrenta, es que se tiende a confundir con otros conceptos como la equidad, la inclusión social y el bienestar. 
INTERVENCIONES URBANAS Y TEJIDO SOCIAL

EN LA CIUDAD DE MÉXICO

La discusión empieza con Durkheim (1997), enfatizando que cuanto menor es la división del trabajo en las sociedades, mayor es la vinculación de los individuos con un grupo social a través de una solidaridad mecánica. Pero esta solidaridad social para los miembros de la sociedad, no representa en su totalidad una realidad, ya que dependen de las instituciones para proveerles bienestar y seguridad. EUROsociAL (2017) la define como:

(...) la cohesión social es un atributo de la sociedad que implica la igualdad de oportunidades para que la población pueda ejercer sus derechos fundamentales y garantizar su bienestar, libertad de discriminación de cualquier tipo, al tiempo que aborda la diversidad. Desde una perspectiva individual, la cohesión social significa la existencia de personas que son parte de la comunidad, participan activamente en diversos ámbitos de toma de decisiones y son capaces de ejercer una ciudadanía activa, la cohesión social implica también el desarrollo de políticas públicas y mecanismos de solidaridad entre individuos, grupos, territorios y generaciones (EUROsociAL, 2017).

Mientras la Fundación Internacional y para Iberoamérica de Administración y Políticas Públicas discute que:

(...) más que un medio o un fin (objetivo), la cohesión social es un principio rector de la acción pública. Su objetivo es la creación de un tejido social que estructure las diferentes comunidades y grupos de un país. Promueve la consolidación de las instituciones democráticas y la implementación de políticas públicas sostenibles que brinden oportunidades a los ciudadanos; garanticen su protección y les permitan desarrollar sus capacidades. Su objetivo es consolidar instituciones y políticas que mejoren el bienestar social y las condiciones de vida de los ciudadanos (FIIAPP, 2011).

Como se puede observar, ambos conceptos son multidimensionales e involucran la participación de ciudadanos que, junto con el gobierno, establezcan las bases para tener un 
INTERVENCIONES URBANAS Y TEJIDO SOCIAL

EN LA CIUDAD DE MÉXICO

sentido de pertenencia y solidaridad, a través de un bienestar basado en igualdad de oportunidades. La Comisión Económica para América Latina y el Caribe (2007), la detalla como "la dialéctica entre mecanismos instituidos de inclusión y exclusión sociales y las respuestas, percepciones y disposiciones de la ciudadanía frente al modo en que ellos operan". Esta definición permite vincular diferentes dimensiones, por ejemplo, la política, la democracia, las instituciones públicas, las instituciones privadas, la economía y la sociedad junto con sus percepciones. De acuerdo con el Laboratorio de Cohesión Social "la cohesión social es un atributo de las sociedades que implica la igualdad de oportunidades para que la población pueda ejercer sus derechos fundamentales y asegurar su bienestar, sin discriminación y atendiendo la diversidad" (a través de AMEXCID, 2016). Como se puede observar, las definiciones discutidas enfatizan un imaginario democrático donde la sociedad es informada y se fomenta su multiculturalismo como mecanismo de inclusión social y participación ciudadana. Consecuentemente, se realiza un acto hipotético en donde las personas tienen confianza hacia las instituciones, el capital social, el sentido de pertenencia y solidaridad, las normas tácitas de convivencia y la participación comunitaria.

Se le da el nombre de intervenciones urbanas a una forma de apropiación de un espacio, lugar, a través de acciones que llevan al sujeto/objeto a hacerse dueño de éste por un periodo determinado de tiempo. Dichas acciones se encuentran fuertemente ligadas al arte, arquitectura y urbanismo. Hay una rama del urbanismo, urbanismo hecho a mano, que involucra a los residentes locales en sus vecindarios o comunidades para hacer trasformaciones urbanas, con sus propias manos y medios (Rosa \& Weiland, 2013). Este proceso empieza con el reconocimiento de un problema por parte de los residentes, seguido por la realización de una idea para resolver los problemas más inmediatos. Esto no es un proceso simple o directo, ya que se deben reconocer oportunidades en los retos para darle un uso creativo a los recursos existentes y forjar asociaciones y relaciones que ayuden a alcanzar objetivos predefinidos que aborden las necesidades que eventualmente asegurarán una mejor calidad de vida para las comunidades. Se infiere que cada intervención es única porque está moldeada por las características del contexto, los individuos que las llevan a cabo y las operaciones que las definen. De acuerdo con Rosa y Weiland (2013), se llevan a cabo 
INTERVENCIONES URBANAS Y TEJIDO SOCIAL

EN LA CIUDAD DE MÉXICO

a escala local, como productos de la cultura y del medio ambiente y se ocupan tanto de la estructura blanda, bienestar físico y emocional, educación, etc., como la remodelación del entorno construido. La mayoría de estos proyectos cae en una de las siguientes taxonomías: recuperación de espacios a través de la construcción de espacio colectivo; mejoramiento del ambiente mediante programas de administración de residuos o agricultura urbana; emprendimiento de naturaleza económica para reducir el desempleo; promocionar actividades de ocio activando espacios públicos o colectivos; y creación de infraestructuras que tengan un impacto positivo en la vecindad enalteciendo la cohesión social.

\section{Diseño como agente de conocimiento}

El diseño ha sido estudiado, por un tiempo prolongado, para determinar teoréticamente el grupo de capacidades, habilidades y resultados que están relacionados a su práctica. Académicos y profesionales lo consideran como un proceso iterativo que se enfoca en observar, sintetizar, generar, analizar y evaluar posibilidades hipotéticas que, subsecuentemente, llegarán a resultados a través de un proceso. Su definición es abundante porque su área de conocimiento esta intrínsecamente relacionada con otras disciplinas, dando oportunidad de cubrir un amplio campo de aplicación. La intersección de enfoques es, en algunos casos, complementaria a la naturaleza de sus dominios, tradiciones de investigación, metodologías, prácticas e impacto social (Alexiou, Johnson, J. \& Zamenopoulos. 2010). En opinión de Mitleton-Kelly $(2010,97)$, artistas y científicos comparten elementos comunes como la exploración de espacios de posibilidad; el uso de emergencia; la co-evolución con sus objetos y sus ciencias, la creación de un nuevo orden; la participación en desarrollos colaborativos; y la utilización de procesos cognitivos creativos.

Los diseñadores son responsables de administrar una amplia gama de competencias que los ayudan a percibir, visualizar, idear, realizar prototipos, modelar, manipular, estimular, soportar riesgo e incertidumbre y pensar ambidiestramente. Su práctica combina el carácter lógico, objetivo y tangible del enfoque científico, y la dimensión intuitiva, subjetiva, efímera y artística del esfuerzo creativo. Como se ha discutido previamente, el diseño es un proceso 
INTERVENCIONES URBANAS Y TEJIDO SOCIAL

EN LA CIUDAD DE MÉXICO

consciente, creativo e inquisitivo, que tiene como objetivo investigar y resolver fenómenos no antes vistos. Esto permite al diseñador nuevas posibilidades en su participación hacia la sociedad. Por ejemplo, puede colaborar en la discusión de temas nacionales como la sustentabilidad (ambiental, económica y social), sociedad inclusiva, salubridad, responsabilidad social y derechos humanos. Su rol es importante en la mejora del mundo, a través de (re) imaginar el futuro de las industrias, ciudades y naciones. Deben ser responsables de motivar y alentar un diálogo abierto con el gobierno, realizadores de políticas, líderes industriales, y miembros de la sociedad acerca de la función de los sistemas actuales. Al nivel industrial, el diseño estimula el desarrollo de capacidades humanas en diferentes industrias, especialmente en las creativas (México) o también llamadas de experiencia (Suecia), culturales (Francia, Estados Unidos, Australia), de derecho de autor (Canadá, Estados Unidos, Australia), de medios y entretenimientos (Hong Kong), o científicas y tecnológicas.

El diseño es un agente de conocimiento que se apoya de la ciencia y el arte como parte íntegra de sus procesos para crear nuevos sistemas. Los diseñadores usan una serie de instrumentos que recolectan datos para facilitar la experimentación y el dialogo (visual) entre las partes interesadas a través de visiones emergentes dirigidas a estimular innovaciones o invenciones útiles para la humanidad. Cuando los diseñadores se involucran en actividades sociales, impulsan observaciones complejas proporcionando varias perspectivas a problemas y desafíos importantes. En opinión de Alexiou, et al. (2010), el proceso de diseño funciona como catalizador, ya que coadyuva a capturar cuestiones, ideas, preocupaciones y significados expresadas por miembros de la sociedad. Esto proporciona una descripción visual de una situación que requiere expresar y transmitir cuestiones simbólicamente interrelacionadas en su conjunto, y atraer la atención a los temas principales y elementos pertinentes. Indudablemente esto facilita la estructuración de problemas y su subsecuente toma de decisiones, desarrollando perspectivas originales que puedan abrir nuevas posibilidades. Bajo la previa discusión, los diseñadores han cuestionado los límites de la disciplina y consecuentemente participado en nuevas funciones, como artífice de decisiones, explorador, facilitador de pensamiento, líder, mediador, navegador de complejidad, negociador, orquestador, pensador crítico, visionario y visualizador de intangibles (Buchanan \& Margo- 
INTERVENCIONES URBANAS Y TEJIDO SOCIAL

EN LA CIUDAD DE MÉXICO

lini, 1995; Hargadon \& Douglas, 2001; Bertola \& Teixeira, 2003; Borja de Mozota, 2006, b; Inns, 2007). Esto se ve traducido en actividades concretas, por ejemplo, cuando son facilitadores sociales deben agilizar, energizar y movilizar el pensamiento de las personas involucradas. Como visualizadores deben sintetizar las posibilidades futuras con entidades físicas, ya que su desafío está asociado con la visualización de entidades abstractas e inteligibles. Cuando son mediadores ofrecen soluciones a múltiples grupos de personas, a menudo interesadas en diferentes perspectivas, necesidades y expectativas. Esto aunado a ser orquestadores, ayuda a planificar futuras ideas, implementaciones y producciones, a través de la exploración de recursos técnicos y contextuales, relevantes para maximizar la creatividad en las primeras etapas de diseño. Finalmente, como navegadores de complejidad ayudan a entender ambigüedades usando teorías complejas que consideran el todo y sus posibilidades.

\section{El diseño como instrumento discursivo}

La sociedad actual se encuentra inmersa en una cultura global y multilingüe, que es guiada por experiencias sensoriales, que representan un nuevo lenguaje. Para que dicha comunicación se establezca y sea entendible, se debe discutir cómo las personas comprenden y entienden la información, las reacciones emocionales que evocan y que están ligadas a la memoria y las limitaciones de éstas en la memoria. Este tema se puede estudiar desde el área de comunicación visual, que está intrínsecamente relacionado con el lenguaje visual, diseño gráfico, teoría de aprendizaje, psicología cognitiva, neurociencia y visualización informativa. Nuestro sistema visual se puede sintetizar en un proceso mental complejo donde primero se observan las imágenes para después explorar y buscar asociaciones en nuestra memoria y con ello usar nuestro conocimiento actual para interpretar e inferir un significado a lo desconocido. La visualización de información, pues, se convierte en un apéndice en la producción de conocimiento artístico, científico, tecnológico y social (Van Wijk, 2005). Porque es un medio que representa estructuras de información multidimensional (bidimensionales y tridimensionales) que requieren de métodos analíticos y visuales/espaciales de razonamiento. La visualización de información sirve como medio de comunicación de 
historias, resultados de investigación o plataformas para manipular y explotar datos. Esta depende de dos factores, medios de producción y resultados. La primera requiere medios analíticos, medios de reproducción y campos de fuentes de conocimiento para su producción. La segunda, es acerca de sus resultados que pueden ser artefactos cognitivos que ayudan a documentar información, transmitir significados, desarrollar la memoria activa, facilitar la indagación y el descubrimiento, soportar las inferencias perceptuales, mejorar la detección y reconocimiento de información, proveer modelos de mundos prácticos y teoréticos y equipar medios que asistan a la manipulación de datos. Consecuentemente el diseño se vuelve esencial en el proceso cognitivo requerido en la creación (codificación) y utilización (decodificación) de intervenciones que centren su trabajo en proveer mensajes, cultura y significado en un contexto.

Varios diseñadores, arquitectos, urbanistas y artistas han experimentado de forma sistemática cómo resultados tridimensionales se convierten en un instrumento discursivo. Por ejemplo, las ciudades de jardines de Ebenezer Howard eran experimentos de diseño impulsados por los sistemas sociales y la creación. El diseño actual de la propia ciudad de Milton Keynes es una serie de experimentos relacionado en el diseño, planificación y gestión de sistemas técnicos complejos. Mitleton-Kelly (2010) va más allá de esto y usa arte como un instrumento para recolectar datos para sistemas sociales complejos. Juilian Burton utiliza el arte para facilitar el proceso llamado "dialogo visual". Will Alsop emplea la pintura y su sinceridad para facilitar posibilidades para acercarse a la comunidad y mejorar su condición. Previamente mencionamos que el diseño puede proporcionar una perspectiva visual y analítica en problemas y desafíos importantes antes, durante y después de proyectos sociales o culturales.

El proceso de diseño puede:

a Capturar las ideas, significados, preocupaciones y cuestiones expresadas en las reuniones, lo que refleja de vuelta temas emergentes visuales, como un catalizador para continuar el debate; 
INTERVENCIONES URBANAS Y TEJIDO SOCIAL

EN LA CIUDAD DE MÉXICO

b Proporcionar una descripción visual de una situación actual, expresar y transmitir cuestiones interrelacionadas, complejas en su conjunto y atraer la atención de un grupo, de modo, que les permita captar rápidamente los temas principales y centrarse en los elementos pertinentes;

c Estructurar problemas para facilitar el sentido de decisiones compartidas, desarrollando perspectivas originales que puedan abrir nuevas posibilidades en las reuniones. Es decir, por un lado el diseñador asume un compromiso y toma una postura en la mejora de la sociedad y su enriquecimiento al momento que desarrolla resultados. Por el otro, los usuarios evalúan dichos resultados a través de su conocimiento, experiencias y sensibilidad hacia la estética, lo funcional y el comportamiento humano.

\section{Metodología}

México, al igual que otras naciones, sufre escasez en investigación acerca del papel del diseño en el contexto social. En las últimas décadas ha habido un impulso al estudio y la documentación de intervenciones de espacios públicos llevados a cabo por ciudadanos en la Ciudad de México. Por tanto, es esencial entender estas iniciativas urbanas (fenómenos) para explorar si el diseño puede asistir de alguna forma en su creación, evolución y consolidación. El constructivismo social ayudó a entender las estructuras fundamentales de la conciencia de un grupo de personas, en relación a sus experiencias en un contexto urbano. Bajo esta filosofía, se asume que los individuos buscan la comprensión del mundo en el que viven y trabajan, a través del desarrollo de significados de experiencias que tienen con ciertos espacios, objetos y/o cosas (Lincoln \& Guba, 1985; Crotty, 1998; Newman, 2000; Schwandt, 2007). Estos son variados y múltiples ya que son negociados a través de interacciones con otras personas junto con normas históricas, sociales y culturales que operan en la vida de estos individuos. El investigador podrá observar dicha complejidad de perspectivas y plantear preguntas amplias y generales para examinar, indagar y desarrollar inductivamente un patrón de significados (Creswell, 2009) a través de dar sentido (o interpretar) las visiones que otros tienen sobre el mundo. Es clave que escuchen lo que las personas dicen y observen lo que hacen en los contextos específicos en los que viven y trabajan, con el fin 
INTERVENCIONES URBANAS Y TEJIDO SOCIAL

EN LA CIUDAD DE MÉXICO

de entender sus escenarios históricos y culturales. Una de las debilidades de esta filosofía es que el pasado de los investigadores da forma a sus interpretaciones. Para contrarrestarlo, tienen que posicionarse en la investigación para reconocer cómo su interpretación se deriva de sus experiencias personales, culturales e históricas.

Un enfoque exploratorio fue requerido para observar y documentar acciones y decisiones tomadas en varias intervenciones suscitadas en una misma ubicación, específicamente U.H. CTM Culhuacán, Sección 7, Zona 8-11. Los métodos usados son casos de estudio longitudinales, etnografía visual, diarios etnográficos, entrevistas y documentación para recoger información que represente la apreciación humana del lugar, espacio, práctica y ritual. Se recurrió a un caso de estudio longitudinal, debido a que un grupo de residentes de la localidad realizaban una serie de rituales en verano y fines de semana que transformaban las áreas públicas. El caso progreso de una intervención temporal que usaba áreas públicas de tránsito para los condóminos hasta una iniciativa de intervención permanente que fue traducida en la construcción de un centro social cultural autónomo en un área gubernamental. Por ello, una serie de casos de estudio descriptivos longitudinales permitirán explorar en su contexto natural un fenómeno, aumentar la evidencia que lo diagnostique, identificar su origen y establecer que se puede hacer al respecto (Gomm, et al., 2000). La fortaleza de este método, es el énfasis que se pone al contexto de estudio para ofrecer un marco de referencia, tanto para el investigador como al lector en la interpretación de los acontecimientos. De igual manera, se llevó una documentación de observaciones, memoria fotográfica e historia gráfica de las intervenciones llevadas a cabo por miembros de la comunidad del lugar de estudio. Esta triangulación ayudó a documentar exhaustivamente la transformación y los efectos de las intervenciones urbanas en la comunidad (Yin, 1994). Ya que el objetivo era observar posibles patrones y vínculos con relevancia teórica en lugar de resultados de una población muestra (Bryman, 1989). Por ello, el documentar actividades por un periodo extendido, da la oportunidad de observar y entender diferentes aspectos de las personas que están envueltas en las intervenciones y su relación con sus dignificados, en lugar de tener análisis basados en la simplificación de categorías (Borja de Mozota, 2006, a; Bruce, et al., 1999; Frias-Peña, 2005; Moustakas, 1994). Una vez terminada la compilación 
de datos, se utilizaron archivos digitales para ordenar las fotografías, documentación y entrevistas de forma accesible a través de aplicaciones de software para restaurar parte o todo el sistema de información y cronología (Pearce-Moses, 2005). Los métodos complementarios nos sirvieron en este caso para comparar una fuente de datos con otra y luego integrar la información para tener una perspectiva más amplia y válida (Hernández-Sampieri, et al., 1998; Creswell, 2009). Por supuesto, los resultados deben tener la lógica de replicación en la que la teoría se pone a prueba en contextos para ver si se ajusta a otro caso. Si no encaja, es probable que las condiciones bajo las cuales la teoría opera necesita ser más precisa en su lógica de replicación.

\section{Procedimientos}

La primera acción fue establecer variables para seleccionar el caso de estudio y confinarlo en un área geográfica para minimizar los efectos externos de su muestra (contexto socio cultural, clima social, recursos, entre otros). Los requerimientos que debían cumplir los casos de estudio fueron los siguientes:

a Realizar iniciativas de intervención urbana, a escala local, por miembros de la comunidad;

b Dirigidas, ya sea para recuperar espacios, a través de la construcción de espacios colectivos o para promocionar actividades de ocio activando espacios públicos;

c Residir en zonas marginales de la Ciudad de México;

d Ser reconocida por los miembros de su comunidad;

e Operar actividades continuas en un espacio;

f Haber estado activo, al menos cincos años;

g Ser una actividad autónoma, con la posibilidad de recibir apoyos de organismos gubernamentales.

Los casos fueron recopilados a través de una investigación secundaria en sitios culturales, diarios locales y nacionales, revistas y medios de comunicación. Un grupo de 25 casos potenciales de estudio fueron encontrados y filtrados a través de una base de datos de la Se- 
INTERVENCIONES URBANAS Y TEJIDO SOCIAL

EN LA CIUDAD DE MÉXICO

cretaría de Cultura de la Ciudad de México. El siguiente paso fue visitar, personalmente los casos para entender su evolución y estructura, a partir de las siguientes preguntas abiertas: ¿por qué empezó este proyecto?, ¿qué inspiró a la comunidad?, ¿dónde están ubicados?, ¿qué tipo de actividades o programas hacen?, ¿qué situaciones se generan?, ¿cómo se desarrolló el proyecto?, y ¿cómo sus resultados han impactado a la comunidad? La información generada permitió tener una instantánea de los mecanismos bajo los cuales los proyectos operaban. Se pudo entender cómo movilizaban a la comunidad para contribuir en las actividades; creaban asociaciones y apalancaban el apoyo; basaban las capacidades existentes para desarrollar y sostener la actividad; y beneficiaban, directa e indirectamente, a los usuarios, residentes y al propio ambiente urbano. Uno de los casos de estudio cumplía con todos los requerimientos y, a efecto de su compresión integral, fue necesario documentar su historia y la transición de los casos que lo forman. El investigador entrevistó a dos miembros activos de las cinco intervenciones que han marcado el caso de estudio.

Paralelamente se elaboró una lista preliminar, con determinantes de diseño, que pudieran coadyuvar en las iniciativas urbanas dirigidas a actividades culturales. Se revisaron referencias bibliográficas para establecer un marco teórico que permitiera contribuir en el desarrollo de modelos para el contexto estudiado. Cuando la lista fue definida, el siguiente paso fue comprender y definir cuáles eran los niveles de medición, administración y lenguaje (Oppenheim, 2000). Se consideraron dos aspectos: tener variables que tuvieran propiedades psicométricas y usar datos cualitativos para tener ideas específicas del caso (Balnaves \& Caputi, 2001). Este sistema ayudó a definir propiedades y operaciones de las diferentes iniciativas urbanas para generar posibles taxonomías. Las variables tomaron como medio de construcción un formato de respuestas de intervalos de escala Likert de 0 a 4 , escala sumatoria (Collins \& Hussey, 1996; Balnaves \& Caputi, 2001). En esta medición, los siguientes números representan cierta respuesta: 0 no; 1 poca medida o escaso; 2 cierta medida o regular; 3 buena medida o bueno; 4 gran medida o muy bueno. Las respuestas fueron agrupadas en diferentes niveles de evaluación (organización, proyecto, servicio y cultura) para facilitar el análisis de las características que definen al caso de estudio (Tabla 1). Por supuesto, esta herramienta fue redefinida a través de la exploración del caso de estudio y entrevistas con un promo- 
INTERVENCIONES URBANAS Y TEJIDO SOCIAL

EN LA CIUDAD DE MÉXICO

tor cultural y dos miembros activos de las intervenciones urbanas. También fue importante contactar a otros especialistas y miembros de otras intervenciones para asegurar que la lista fuera válida y confiable. Con la información obtenida fue posible producir una lista que reflejara los problemas con los que se enfrentaron los sujetos del estudio.

\begin{tabular}{|c|c|}
\hline \multicolumn{2}{|c|}{ Tipo de organización } \\
\hline \multicolumn{2}{|c|}{$\begin{array}{l}\text { Taxonomía cultural } \\
\text { Organización cultural } \\
\text { Organización con uso intensivo de recursos creativos } \\
\text { Organización proveedora de cultura especializada } \\
\text { Organización dependiente de proveedores externos de cultura }\end{array}$} \\
\hline \multicolumn{2}{|c|}{ Proyecto } \\
\hline $\begin{array}{l}\text { Actividades evaluadas } \\
\text { Planeación } \\
\text { Organización } \\
\text { Implementación y monitoreo } \\
\text { Evaluación }\end{array}$ & $\begin{array}{l}\text { Nivel de implementación } \\
\text { Experto } \\
\text { Competente } \\
\text { Aprendiz } \\
\text { Elemental }\end{array}$ \\
\hline \multicolumn{2}{|c|}{ Servicio } \\
\hline \multicolumn{2}{|l|}{$\begin{array}{l}\text { Experiencias cubiertas } \\
\text { Superiores } \\
\text { Aumentadas } \\
\text { Conocidas } \\
\text { Básicas }\end{array}$} \\
\hline \multicolumn{2}{|c|}{ Cultura } \\
\hline \multicolumn{2}{|c|}{$\begin{array}{l}\text { Actividades y comportamientos que imparten en el grupo comunitario } \\
\text { de las intervenciones urbanas } \\
\text { Activo } \\
\text { Realizador } \\
\text { Reactivo } \\
\text { Pasivo }\end{array}$} \\
\hline
\end{tabular}

Tabla 1. Taxonomías de intervenciones culturales.

Para obtener confiabilidad y validez en la construcción metodológica en el caso de estudio, fue necesario el uso de una base de datos, y evidencia de campo con citas en el reporte (Healy \& Perry, 1998). Esta investigación alcanzó validez en su construcción, usando múltiples fuentes de evidencia y revisión con informantes claves durante y después que se escribió un borrador del caso de estudio. La investigación, además, buscó lograr validez interna 
INTERVENCIONES URBANAS Y TEJIDO SOCIAL

EN LA CIUDAD DE MÉXICO

y externa identificando discrepancias y garantizando que los resultados fueran representativos. Esto fue posible a través de una serie de intervenciones y seguimientos utilizando diferentes técnicas como talleres, comentarios, observaciones participativas, documentación, documentos de archivos y objetos físicos. Los resultados del estudio fueron presentados a los participantes para alcanzar validez. Entrevistas semiestructuradas fueron aplicadas a las participantes de las diferentes intervenciones para obtener evidencia adicional para apoyar o rechazar los resultados recogidos.

\section{Escenario}

La Ciudad de México ha experimentado una transformación en su agenda cultural, social y urbana ofreciendo a sus habitantes y visitantes un sabor cosmopolita. Este cambio empezó en el año de 1997, cuando un partido de izquierda asumió el mandato de la capital. Entre las primeras acciones que tomó el jefe de gobierno capitalino fue invertir recursos en programas sociales (cultural, educativo y recreativo) para reducir la brecha entre la población rica y pobre. Por ejemplo, en el ámbito cultural se crearon espacios para promover localmente la lectura, pues existía un acentuado rechazo a dicha actividad, a lo que se sumaba el abandono de las instalaciones gubernamentales que ofrecían dichos servicios. En este contexto, el jefe de gobierno decretó la creación del Instituto de Cultura de la Ciudad de México, recayendo la dirección del mismo, en Alejandro Aura, quien se dio a la tarea de instalar 1000 espacios llamados "club de la lectura" con un acervo de 600 libros en cada uno. Con este programa se acercaron los libros a los habitantes de la ciudad, residentes en colonias, barrios, unidades habitacionales y pueblos. Bajo esta nueva administración, se dio prioridad a la descentralización como estrategia, para lograr una distribución eficiente de recursos dirigidos a infraestructura y actividades relacionadas a la cultura. Fue clave involucrar a ciudadanos en la toma de decisiones sobre sus intereses culturales y sociales. Este programa se convirtió en un modelo de gestión comunitaria entre asociaciones culturales. En 2002, el Instituto de Cultura de la Ciudad de México se convirtió en Secretaría, permitiéndole tener el mismo nivel de gestión, que las políticas educativa y social. 
INTERVENCIONES URBANAS Y TEJIDO SOCIAL

EN LA CIUDAD DE MÉXICO

No obstante el nivel de decisión de la Secretaria de Cultura de la Ciudad de México aumentó, su rendimiento se vio disminuido en virtud de la política de austeridad implementada por el jefe de gobierno. Así, de 1014 libro clubes se bajó a 300 y el número de promotores culturales bajó de cien a cincuenta (Gaspar-Guadarrama, 2012). Aquellos clubes que continuaron con la promoción de actividades culturales, se convirtieron en lugares comunitarios de gestión autónoma, que a veces carecían de orientación y entrenamiento. Esta situación fue aprovechada por la Secretaria de Cultura para crear programas de financiación que ayudaran a proyectos comunitarios autónomos para promover y mantener sus actividades. Una gran mayoría de estos emprendimientos se conformaban asociaciones civiles. Desafortunadamente, existe una falta de documentación sobre el universo de proyectos culturales y sociales establecidos por la sociedad civil organizada, incluyendo centros culturales autónomos en la Ciudad de México. Por supuesto, hay bases de datos elaboradas por diferentes secretarías, en las que se documentan todos aquellos proyectos a los que se les concedieron recursos financieros para desarrollar sus actividades culturales. La actual administración sigue invirtiendo en cultura a través de programas como desarrollo cultural comunitario e inclusión: intervenciones y desarrollo artístico; estímulos a la creación artística y cultural; vinculación y gestión de lectura y cultura; servicios comunitarios, entre otros.

\section{Caso de estudio}

La delegación de Coyoacán (Figura 1) establecida en 1928, cuando Ciudad de México se dividió en 16 delegaciones administrativas. Es la décima delegación más grande con el 7.2\% de la población y se encuentra rodeada por las delegaciones Benito Juárez, Iztapalapa, Xochimilco, Tlalpan y Álvaro Obregón. De acuerdo con la clasificación diseñada por el Programa de las Naciones Unidas para el Desarrollo, la mayoría de sus habitantes cuentan con alta calidad de vida. Se encuentra entre los primeros lugares a nivel nacional e internacional si se consideran sus niveles de ingresos, salud y educación. Sin embargo, existen comunidades donde prevalece el vandalismo junto con delitos como robo, tráfico de drogas, asaltos y homicidios; que generan solo el $7.2 \%$ de todos los reportes de crímenes en la Ciudad. Sumido dentro de este contexto se encuentra la U.H. CTM Culhuacán Zona 7 sección 8-11, donde se localiza el caso de estudio. 
INTERVENCIONES URBANAS Y TEJIDO SOCIAL

EN LA CIUDAD DE MÉXICO

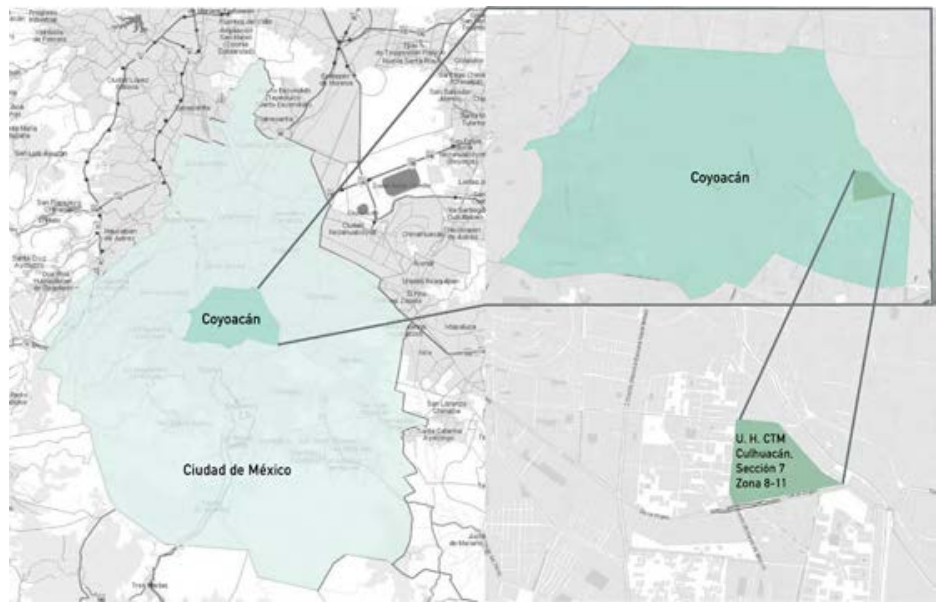

Figura 1. Delegación Coyoacán, Sección 7 CTM Culhuacán.

\section{Los comienzos (1987-1992). Información clave primera iniciativa}

Ubicación | dos áreas de tránsito y un estacionamiento

Actividades | culturales, sociales y recreativas

Usuarios | niños, adolescentes y padres de familias

Duración | 1 año

Impacto obtenido | mejoró la relación vecinal; fomentó la participación vecinal, ya que incluyó a miembros de bandas

La sección siete forma parte de un complejo habitacional de 29 mil viviendas de corte social, agrupadas en diecinueve secciones construidas en el año 1977. En los primeros diez años de existencia del complejo, el mantenimiento fue proporcionado por el Instituto del Fondo Nacional de la Vivienda para los Trabajadores (INFONAVIT), el cual promovió la construcción. El apoyo se caracterizó por una serie de contradicciones por la poca transparencia de la administración que fue designada para administrar los recursos económicos aportados por el INFONAVIT. En 1982 se aprobó el Programa Parcial de Desarrollo Urbano del Distrito Federal para regular el uso y reserva de suelo con el objetivo de respetar el derecho de los ejidatarios, comuneros, y vecinos, y las actividades productivas de la zona. Cada año se elegía un jefe de manzana en cada sección para realizar mejoras en el área con apoyos financieros proporcionados por el gobierno. Esta oportunidad junto con la falta de servicios coadyuvó a que algunos vecinos se organizaran por secciones. 
INTERVENCIONES URBANAS Y TEJIDO SOCIAL

EN LA CIUDAD DE MÉXICO

Los miembros de la zona eligieron en 1987 a una jefa de manzana que era empleada federal, madre y ama de casa. Por su perfil empezó a incentivar la relación entre vecinos a través de actividades culturales, sociales y recreativas dirigidas a niños y adolescentes. Las primeras iniciativas se llevaron a cabo en áreas comunes y estacionamientos de la zona con actividades relacionadas a fechas importantes del calendario nacional. Por ejemplo, en épocas navideñas se transformó el área común (A), que se encuentra rodeada por edificios, en un escenario de teatro, para la escenificación de una pastorela, con la participación de niños, niñas y jóvenes de la comunidad. Otro espacio público de tránsito (B), se intervino para realizar convivios culturales y sociales, en ocasión del día de niño, el día de la madre, entre otros. En el verano se intervino un estacionamiento $(C)$, utilizándolo como espacio híbrido para realizar actividades deportivas, con la participación de niños y adolescentes. Lo que compartían estos lugares es que son espacios públicos y de tránsito que los vecinos y peatones ajenos utilizan continuamente.

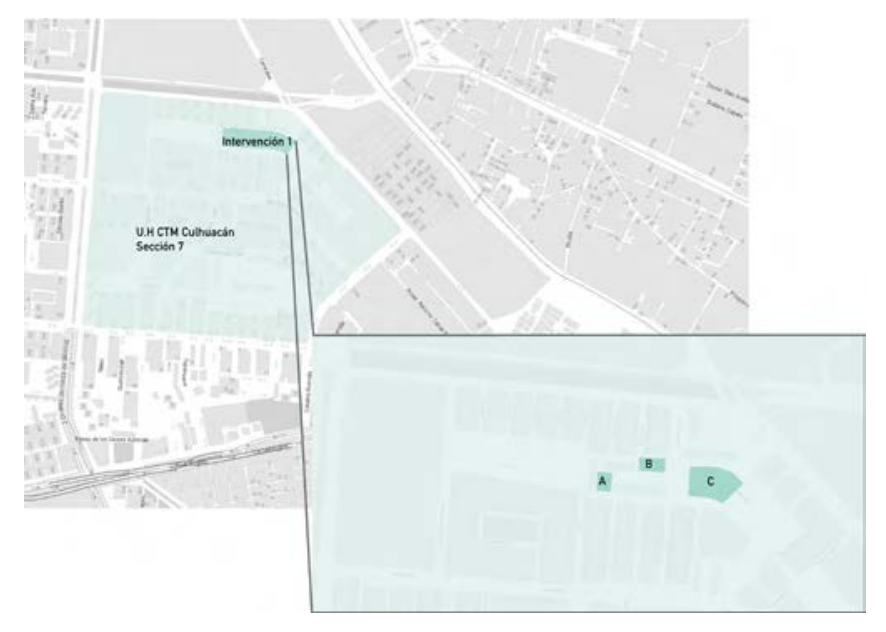

Figura 2. Primera intervención ciudadana

\section{Información clave segunda iniciativa}

Ubicación | dos áreas de tránsito y dos estacionamientos | institución gubernamental, espacios privados y públicos | institución educativa

Actividades | culturales, sociales y recreativas

Usuarios | niños y adolescentes

Duración | 3 años 
INTERVENCIONES URBANAS Y TEJIDO SOCIAL

EN LA CIUDAD DE MÉXICO

Impacto obtenido | mejoró la relación entre las personas de la localidad; fortaleció la relación entre padres e hijos; contribuyó a fortalecer los negocios locales; redujo la violencia de la zona.

Un año después de que la jefa de manzana fue elegida, se dio a conocer la discontinuidad del apoyo por parte del gobierno. A pesar de la pérdida de los recursos financieros, un grupo de padres de familia y adultos jóvenes decidieron continuar con este tipo de actividades dando pie a la segunda iniciativa urbana. La primera decisión fue realizar actividades, que involucraran a un mayor número de personas y que su duración fuera mayor. Se discutieron las posibles actividades, las cuales dependían de las personas involucradas en la actividad, y así como los lugares susceptibles de llevarlas a cabo. Se decidió, por consenso que la iniciativa se implementara en el periodo vacacional de verano, para apoyar a padres de familia que trabajaban. Se denominó la iniciativa "el taller de la experiencia", con una duración de tres años. Intervinieron áreas públicas y privadas, para transformar los espacios en aulas de clases, áreas deportivas y exhibiciones artísticas, en donde niños y adultos compartían experiencias.

En el primer año se llevaron a cabo actividades artísticas y recreativas. Los espacios ocupados fueron dos explanadas, ubicadas entre edificios ( $A 1 ; A 2)$, que se utilizaban como aulas artísticas, salones de lectura y laboratorios de fotografías. El estacionamiento (A3) y un camellón (A4) eran ocupados para realizar actividades recreativas. Durante ese año, cinco adultos y cinco adultos jóvenes fueron responsables de las actividades en las que participaron 90 niños y niñas. En el segundo año el número de participantes se incrementó a 120 niños, y con ello, el de los monitores y talleristas. Se integraron nuevas actividades, como astronomía y ajedrez a los ya existentes. A los espacios ya ocupados se incluyeron otros para realizar actividades por grupos de edades, así como para exhibir los resultados de la actividad. Se utilizaron dos estacionamientos (B1; B2) para las actividades grupales. Al término de las actividades del verano, se organizó un campamento (B3), en el que participaron la comunidad del curso y padres de familia, para fortalecer el sentido de comunidad. B4 es un Centro Cultural del Gobierno que fue prestado para que los niños exhibieran las 
INTERVENCIONES URBANAS Y TEJIDO SOCIAL

EN LA CIUDAD DE MÉXICO

habilidades adquiridas durante el verano. Para el tercer año, el número de niños aumentó a 160 y por consiguiente los responsables pidieron apoyo a una institución educativa (C1) para usar las instalaciones por cuatro semanas. De igual manera, se solicitó a la delegación de Coyoacán apoyo de transporte, que permitió visitar museos y actividades culturales. Al término de esta versión del "taller de la experiencia", se decidió que no podía haber continuidad por parte de algunos miembros del grupo original, porque sus actividades laborales y educativas no se los permitían.

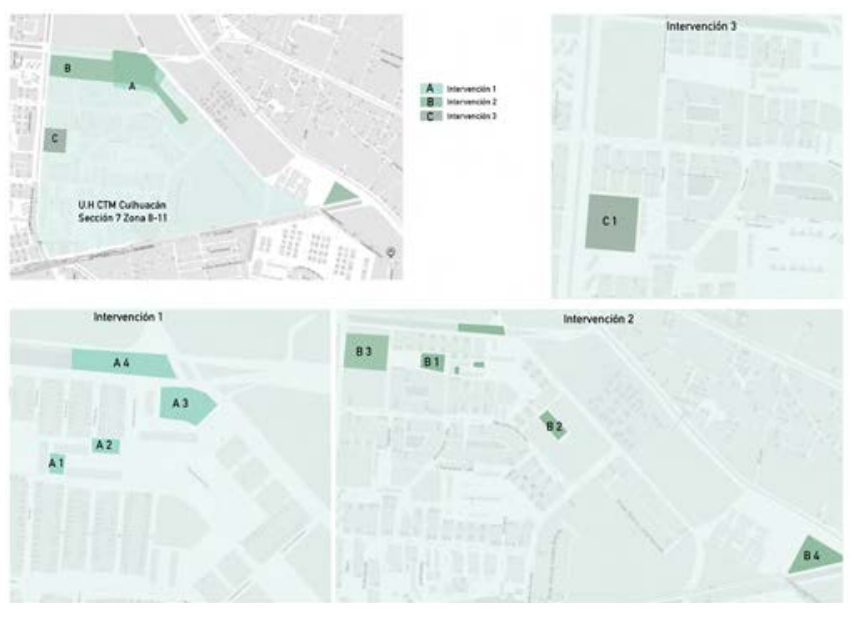

Figura 3. Segunda intervención ciudadana "taller de la experiencia".

Ahora bien, entre las bondades generadas por esta experiencia mencionaremos las siguientes: las personas de la comunidad fueron las primeras beneficiadas, en virtud de que se construyeron redes de apoyo y comunicación. En segundo término, los padres de familia fortalecieron lazos de comunicación con sus hijos. En tercer lugar, los niños, al participar en actividades a las que antes no tenían acceso, compartieron experiencias sociales que promovían empatía como vecinos y compañeros. Finalmente, se beneficiaron los vecinos cuyos negocios registraron un incremento en sus ventas.

\section{Información clave tercera iniciativa}

Ubicación | dos áreas de tránsito, camellón, una accesoria, dos salas de casa habitación Actividades | lúdicas, artísticas y recreativas

Usuarios | niños 
INTERVENCIONES URBANAS Y TEJIDO SOCIAL

EN LA CIUDAD DE MÉXICO

Duración | 2 años

Impacto obtenido | fortaleció la relación entre miembros de la localidad; creó un sentido de comunidad entre miembros partícipes de la iniciativa urbana; fortaleció un grupo de trabajo de la comunidad; contribuyó a fortalecer los negocios locales; redujo la violencia en la zona.

La tercera intervención se orientó a la facilitación de actividades, debido a que un grupo de personas abandonaron el proyecto. Quienes continuaron, tomaron los acuerdos: impartición de los talleres de verano, reducir la matrícula de participantes, organizar a monitores y talleristas en comisiones de coordinación, académica, adquisiciones, finanzas, aseo y vialidad. La comisión de coordinación jugaba un papel central, al tener que establecer una vinculación entre las diferentes comisiones. La académica se conformó con monitores y talleristas, era la responsable de recibir solicitudes para impartir talleres. La comisión de adquisiciones, en función del número de participantes, cuantificaba los recursos materiales necesarios para cada taller, como: pintura, pinceles, papel, equipos de ajedrez, libros, cortinas, gorras (color rojo y azul), estambres, cera de Campeche, escobas, bolsas para la basura, entre otros. Una vez cotizados lo precios, las comisiones en asamblea elaboraban los presupuestos de ingresos y gastos. A partir de ese momento, la comisión de finanzas era la responsable de administrar y proveer recursos económicos para desarrollar el proyecto. En el desarrollo de la iniciativa, se hacían proactivas las comisiones de aseo y vialidad, una para mantener en condiciones de ser utilizados los espacios públicos y privados; y la otra, para apoyar a los monitores y niños en el cruce de vialidades.

En reuniones de trabajo se abordaban las temáticas referidas al objetivo de la iniciativa, los recursos financieros, y la intervención de espacios públicos y privados. Se definió que el objetivo general del curso de verano era proporcionar a las niñas y los niños, a través de actividades manuales, lúdicas, artísticas (danza, pintura, literatura y cine) y ejercicio físico, la posibilidad de estimular su creatividad, sensibilidad y emociones. En relación a los recursos financieros, se estableció por consenso que monitores y padres de familia, no serían objeto de retribución alguna, ya que los recursos se destinaban a los talleres, instalaciones y transporte. La definición de espacio fue clave porque se utilizaron lugares públicos y priva- 
dos para convertirlos en "salones de clase" (Fig. 4). Los lugares públicos fueron la plancha encementada, denominada "la canchita" (A), usada para impartir gimnasia rítmica y danza regional; el área verde adyacente, se convirtió en el salón "Ignacio Manuel Altamirano" (B), para el taller de literatura (animación a la lectura, narración de cuentos y lecturas de poemas); y el camellón de la avenida Santa Ana fue asignado para el ejercicio físico (C). Los lugares privados fueron: una accesoria (D), la sala de una vivienda (E) y la sala/comedor de otra vivienda (F), a los cuales les fueron asignados nombres de culturas prehispánicas.

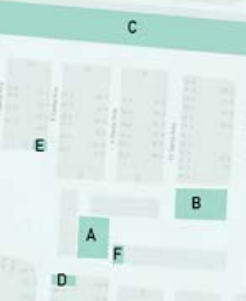

Figura 4. Tercera intervención ciudadana "curso de verano".

Esta intervención duró dos años y se caracterizó por las reuniones sabatinas, con la participación de todas las comisiones en las que se evaluaban las actividades realizadas en la semana. En ambas intervenciones, fue práctica que, en la cuarta semana, se convocara a la comunidad a la clausura del curso de verano, para observar los logros obtenidos, a partir de la exposición de trabajos manuales, declamación de poemas y presentación de danza regional y dibujos. Como número final, la comisión de finanzas rendía un informe puntual de los ingresos y gastos generados por el curso de verano. La clausura propiciaba que los vecinos interactuaran y experimentaran el sentido de pertenencia a una comunidad. Durante ese tiempo las bandas cuidaban y respetaban a los partícipes de la intervención, porque en su opinión estos trataban de mejorar la comunidad y a las nuevas generaciones. Esta última iniciativa da pie a la formalización de actividades, ya que se contaba con una infraestructura comunitaria básica. 
INTERVENCIONES URBANAS Y TEJIDO SOCIAL

EN LA CIUDAD DE MÉXICO

\section{La transición (1999-2002). Información clave cuarta iniciativa}

Ubicación | un área de tránsito y área privada

Actividades | lúdicas y artísticas

Usuarios | todo el público

Duración | 13 años

Impacto obtenido | crearon nuevas redes de comunicación entre miembros de diferentes localidades; estableció una relación con un organismo gubernamental; ofreció actividades culturales y lúdicas a miembros de la comunidad de forma gratuita; promocionó la lectura; redujo la violencia de la zona.

Las iniciativas urbanas fueron desapareciendo paulatinamente, aunque se hacían actividades intermitentes. Durante cinco años, la comunidad de la sección siete olvidó los lazos comunitarios y sucumbió a tres tipos de problemas: el mantenimiento de la unidad, la relación vecinal y el incremento de actos delictivos. La unidad habitacional, junto con su infraestructura, se deterioró con el paso de los años, generando una serie de problemas: abastecimiento irregular de agua potable por severos daños en la red hidráulica; falta de iluminación al interior de la unidad por la falta de mantenimiento; apropiación indebida de espacios (áreas comunes) por parte de los vecinos y deterioro acentuado de la infraestructura de los edificios. Esta decadencia llevó a la proliferación de robo de autopartes, asalto a comercios y transeúntes, y al tráfico de drogas por las bandas delincuenciales de la unidad. La administración prácticamente no existía, la Ley Condominal era letra muerta y no había una cultura de pago de cuotas para mantenimiento en la unidad.

En este contexto nace la cuarta intervención. En 1997, el entonces Gobierno del Distrito Federal convocó a los ciudadanos, mediante una iniciativa de ley, a la organización de "Bibliotecas de Barrio". La nueva iniciativa urbana se concretaba en la figura del "Libro Club", cuyo objetivo expreso era poner al alcance de los habitantes de pueblos, barrios, colonias y unidades habitacionales, libros de literatura. En esta convocatoria participan dos miembros originales y sus hijos, quienes fueron capacitados para organizar y administrar el acervo bibliográfico. En virtud de no contar con un espacio para el funcionamiento del libro club, se 
solicita a los condóminos del edificio la autorización para ocupar un espacio de área verde y levantar una construcción provisional para resguardo de los libros (Figura 5). Se organizaron los libros por género literario y se consiguieron por donación libreros y algunas sillas. Es así como el 29 de julio de 1999, se inaugura formalmente el libro club "Efraín Huerta" con una dotación inicial de seiscientos libros. El procedimiento para el préstamo de libros, es que el lector seleccione el libro de su interés, registre su nombre, domicilio, teléfono junto con el título en un cuaderno ex profeso para ello. Acto seguido el lector dispone del material elegido y al devolverlo, puede disponer de otro. Los responsables del libro club "Efraín Huerta" (A) instrumentaron medidas para acercar a la comunidad e ir formando lectores. Es oportuno recordar que la población la conformaban empleados del gobierno, del sector privado e informal que, en su mayoría, pertenecen a la clase media baja, con una escolaridad de nueve años. En atención a este escenario, se exhibían seiscientos libros en "la canchita" (B) hasta por nueve horas diarias. Como actividad complementaria, el Instituto de Cultura de la Ciudad de México, enviaba a un profesional para hacer lecturas en voz alta al público asistente. Como actividad complementaria, el acervo bibliográfico se incrementó con algunas donaciones de los vecinos. En resumen, después de treinta y seis meses de actividad ininterrumpida se tenían 598 socios (cada lector se convierte en socio) y se habían prestado 18,900 libros, un promedio de diecisiete libros diarios. El $70 \%$ de los lectores eran niños y niñas; el $20 \%$ se componía de jóvenes y el 10\% adultos mayores, en donde la mayoría eran mujeres. A través de la documentación de los préstamos se advirtió que el radio de influencia trascendía a la sección siete ya que acudían lectores que residían a varios kilómetros del lugar. 


\section{La institucionalización (2002-2013). Información clave quinta iniciativa}

Ubicación | un área privada junto con áreas verdes

Actividades | lúdicas, artísticas y recreativas

Usuarios | todo el publico

Duración | 11 años

Impacto obtenido | crearon nuevas redes de comunicación entre miembros de diferentes localidades; ofreció a los miembros de la comunidad servicios culturales a un costo accesible; redujo la violencia de la zona.

En el año 2000, el Gobierno del Distrito Federal puso en marchar el programa de Rescate de Unidades Habitacionales (PRUH), operado por la Procuraduría Social del Distrito Federal. En función del programa, les corresponde a los condóminos de la sección 7 ser convocados a presentar proyectos que mejoren la calidad de vida de la comunidad, los cuales fueron sometidos a votación en la asamblea ciudadana celebrada en abril. Se entregaron cuatro proyectos; por mayoría de votos la asamblea acordó la construcción de un inmueble para desarrollar un proyecto cultural. En cumplimiento de la normatividad, la Asamblea General Ciudadana eligió a las comisiones de Administración y Vigilancia, para que se apliquen $\$ 862,000$ (ochocientos sesenta y dos mil pesos 00/100 M.N.) al proyecto abordado. Al año siguiente, los miembros responsables del proyecto presentaron iniciativas al gobierno de la ciudad para obtener en donación un terreno (Fig. 6), que eran propiedad pública, para construir el centro cultural. En el mismo año, se conformó una asociación civil para obtener los recursos financieros que fueron proporcionados por el gobierno. En el verano de 2002, fue inaugurada la quinta intervención por el jefe de gobierno ante la comunidad.

Para su adecuado funcionamiento, los administradores y maestros elaboraron los documentos básicos que registraban puntualmente la misión y el reglamento normativo. Su misión fue crear conciencia de los problemas esenciales que aquejan a la comunidad, con el fin de establecer una red que ayudara a corregirlos de manera objetiva y oportuna. Los miembros creían que era posible proveer a los habitantes con instrumentos que ampliaran su visión a través de los siguientes objetivos: 
1 Difundir intensivamente y extensivamente la cultura;

2 Desarrollar una concepción dinámica, orgánica y estructurada de las diferentes facetas de la cultura;

3 Incrementar la conciencia de la comunidad acerca de los problemas principales que la afectan, para proveer soluciones organizadas y colectivas;

4 Alentar a niños y jóvenes al hábito de la lectura y otras ofertas culturales como cine de arte, teatro, pintura, para contribuir a una perspectiva aguda e inteligente; y

5 Fomentar el entretenimiento colectivo, la comunicación para que disminuyan los prejuicios y conflictos entre la comunidad.

Su oferta cultural comenzó oficialmente a principios del 2003 (A1), con más de doscientas personas asistiendo a uno de los cuatro seminarios culturales: epistemología, filosofía, crítica de cine y teatro, o tres clases recreativas: karate, hawaiano y artesanías. El objetivo fue ofrecer actividades que eran difíciles de financiar para las personas que vivían en estas zonas marginales. A los administradores y profesores (talleristas) les quedó muy claro que el proyecto cultural debía ser un referente ético y moral, incluyente y respetuoso de la manera de ser y pensar de otro. Consecuentemente, a través de las actividades programadas se debían dar instrumentos a las personas para alentarlos a ponerse de acuerdo y actuar organizadamente para lograr una mejor calidad de vida. Mientras tanto, la biblioteca se fue conformando con donaciones de los vecinos y adquisiciones hechas por la administración.

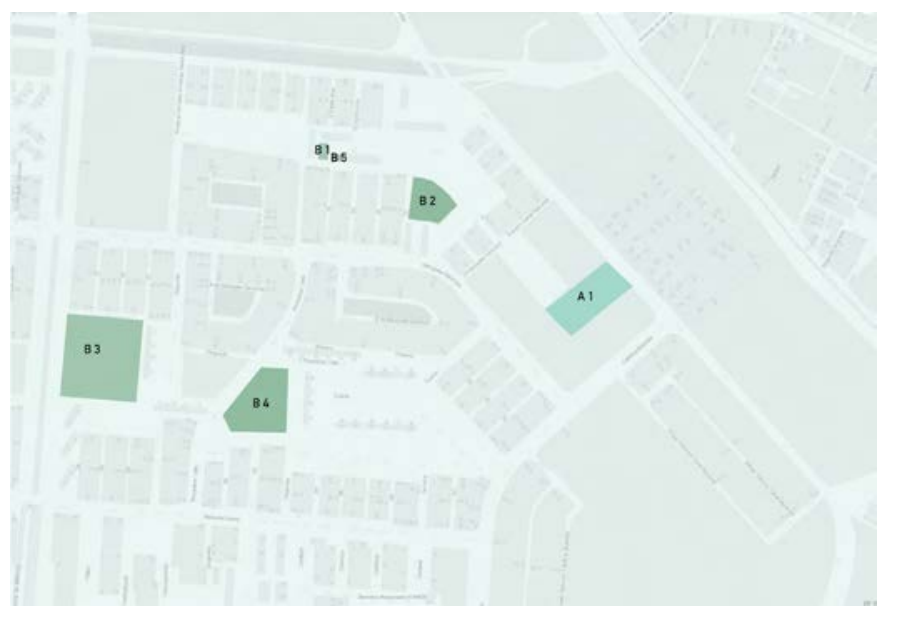


INTERVENCIONES URBANAS Y TEJIDO SOCIAL

EN LA CIUDAD DE MÉXICO

El año 2005, fue un año clave en el declive de la iniciativa. Por un lado, se empezaron a registrar problemas profundos cuando tres de cinco miembros de la administración, desviaron recursos financieros de forma indebida. Esto llevó a la generación de tres deudas: $\$ 34,784$ MXN (asociado 1); $\$ 25,000$ MXN (asociado 2); y $\$ 8,215$ MXN (asociado 3). Por otro lado, se fue reduciendo la oportunidad de abrir más cursos relacionados a cultura o arte. Entre 2005 y 2011, hasta veintiún cursos se crearon haciendo hincapié en las actividades recreativas. Para el año 2012, los conflictos dentro de la asociación civil se multiplicaron tanto que el presidente de la asociación civil fue agredido físicamente y amenazado de muerte por dos miembros de la asociación civil. Por cuestión de salud y seguridad, el presidente tuvo que abandonar el proyecto. Con lo cual el acceso al caso fue concluido.

\section{Información clave sexta iniciativa}

Ubicación | un área pública y tres áreas gubernamentales

Actividades | lúdicas y artísticas

Usuarios | niños y adultos mayores

Duración | 7 años

Impacto obtenido | crearon nuevas redes de comunicación entre miembros de diferentes localidades; dependió de un organismo gubernamental; dio acceso a miembros de la comunidad a servicios culturales de manera gratuita; redujo la violencia de la zona.

En el mismo año del 2005, el presidente de la asociación civil usó su experiencia de casi dieciocho años para buscar financiamiento para proyectos culturales, a través de la Secretaría de Cultura de la Ciudad de México. Como no existía apoyo de los asociados decidió llevar a cabo actividades utilizando la cuarta intervención. De ahí surgió el proyecto "Cascabel" (Figura 6, B1), el cual organizaba actividades culturales gratuitas tales como dibujo, pintura, cine, teatro, música e iniciación a la creación literaria. Este proyecto duró cinco años, en los cuales cada día sábado, un promedio de setenta personas participaban por sesión. Varios residentes fueron beneficiados, particularmente niños y adultos mayores. En el año 2012, este proyecto evolucionó a un programa para abuelos lectores, con el fin de devolver la dignidad a los sectores más desprotegidos y reconocer a miembros invisibles de la comu- 
INTERVENCIONES URBANAS Y TEJIDO SOCIAL

EN LA CIUDAD DE MÉXICO

nidad. Se animó a abuelos y abuelas a leer en espacios públicos y privados para fomentar la lectura entre las generaciones más jóvenes. Se programaban actividades para niños y niñas en hospitales, casas hogar y escuelas públicas. Se integraron 12 abuelas y abuelos cuyas edades fluctuaban entre sesenta y setenta y nueve años de edad. Al final la actividad lectora se estableció en un kínder (B2), dos escuelas primarias (B3, B4) y al aire libre de la "canchita" anexo al espacio de la cuarta intervención (B5). Los resultados reportaron un fortalecimiento en los lazos de afecto entre los miembros de la actividad y los estudiantes de kínder y primaria.

\section{Discusión}

El análisis de la información fue dividido en secciones: la primera discute las características del contexto con el fin de enfatizar el tipo de operaciones que llevaban a cabo y cómo el diseño puede ser usado en las intervenciones. La segunda, decodificó características generales de dos intervenciones para determinar taxonomías.

\begin{tabular}{|c|c|c|c|c|c|c|}
\hline & Intervención 1 & Intervención 2 & Intervención 3 & Intervención 4 & Intervención 5 & Intervención 6 \\
\hline Ubicación & $\begin{array}{l}\text { Dos áreas de } \\
\text { tránsito y un } \\
\text { estacionamiento }\end{array}$ & $\begin{array}{l}\text { Dos áreas de } \\
\text { tránsito, dos } \\
\text { estacionamientos, } \\
\text { una institución } \\
\text { gubernamental, } \\
\text { dos áreas privadas } \\
\text { y una entidad } \\
\text { educativa }\end{array}$ & $\begin{array}{l}\text { Dos áreas de } \\
\text { tránsito, un } \\
\text { camellón, una } \\
\text { accesoria y dos } \\
\text { salas de casa } \\
\text { habitación }\end{array}$ & $\begin{array}{l}\text { Un área de } \\
\text { tránsito y una } \\
\text { área privada }\end{array}$ & $\begin{array}{l}\text { Un área privada } \\
\text { junto con áreas } \\
\text { verdes }\end{array}$ & $\begin{array}{l}\text { Un área pública } \\
\text { y tres áreas } \\
\text { gubernamentales }\end{array}$ \\
\hline Actividades & $\begin{array}{l}\text { Culturales, } \\
\text { sociales y } \\
\text { recreativas }\end{array}$ & $\begin{array}{l}\text { Culturales, sociales } \\
\text { y recreativas }\end{array}$ & $\begin{array}{l}\text { Lúdicas, artísticas } \\
\text { y recreativas }\end{array}$ & $\begin{array}{l}\text { Lúdicas y } \\
\text { artísticas }\end{array}$ & $\begin{array}{l}\text { Lúdica, artísticas } \\
\text { y recreativas }\end{array}$ & $\begin{array}{l}\text { Lúdicas y } \\
\text { artísticas }\end{array}$ \\
\hline $\begin{array}{l}\text { Responsable } \\
\text { | Participante }\end{array}$ & Jefe de manzana & $\begin{array}{l}\text { Padres de familia y } \\
\text { adultos jóvenes }\end{array}$ & $\begin{array}{l}\text { Padres de familia } \\
\text { y adultos jóvenes }\end{array}$ & $\begin{array}{l}\text { Cuatro } \\
\text { responsables }\end{array}$ & $\begin{array}{l}\text { Asociación civil } \\
\text { conformada por } \\
\text { cinco personas }\end{array}$ & $\begin{array}{l}\text { Dos responsables } \\
\text { y adultos } \\
\text { mayores lectores }\end{array}$ \\
\hline Usuarios & $\begin{array}{l}\text { Niños, } \\
\text { adolescentes y } \\
\text { padres de familias }\end{array}$ & $\begin{array}{l}\text { Niños y } \\
\text { adolescentes }\end{array}$ & Niños & Todo el público & Todo el público & $\begin{array}{l}\text { Niños y adultos } \\
\text { mayores }\end{array}$ \\
\hline Duración & 1 año & 3 años & 2 años & 13 años & 11 años & 7 años \\
\hline
\end{tabular}


INTERVENCIONES URBANAS Y TEJIDO SOCIAL

EN LA CIUDAD DE MÉXICO

\begin{tabular}{|c|c|c|c|c|c|c|}
\hline $\begin{array}{l}\text { Impacto } \\
\text { obtenido }\end{array}$ & $\begin{array}{l}\text { Mejor relación } \\
\text { vecinal y } \\
\text { participación } \\
\text { vecinal }\end{array}$ & $\begin{array}{l}\text { Mejor relación } \\
\text { entre vecinos, } \\
\text { fortaleció la } \\
\text { relación entre } \\
\text { padres e hijos y } \\
\text { negocios locales, y } \\
\text { redujo la violencia } \\
\text { de la zona }\end{array}$ & $\begin{array}{l}\text { Fortaleció la } \\
\text { relación entre } \\
\text { vecinos y un } \\
\text { grupo de } \\
\text { trabajo, se creó } \\
\text { un sentido de } \\
\text { comunidad } \\
\text { y redujo la } \\
\text { violencia de la } \\
\text { zona }\end{array}$ & $\begin{array}{l}\text { Crearon redes } \\
\text { locales de } \\
\text { comunicación, } \\
\text { se estableció } \\
\text { una relación con } \\
\text { un organismo } \\
\text { gubernamental, } \\
\text { ofreció servicios } \\
\text { gratuitos, } \\
\text { promocionó la } \\
\text { lectura y redujo } \\
\text { la violencia de la } \\
\text { zona }\end{array}$ & $\begin{array}{l}\text { Crearon redes } \\
\text { zonales de } \\
\text { comunicación, } \\
\text { se estableció } \\
\text { una relación con } \\
\text { un organismo } \\
\text { gubernamental, } \\
\text { ofreció servicios } \\
\text { culturales a } \\
\text { costos accesible, } \\
\text { y redujo la } \\
\text { violencia de la } \\
\text { zona }\end{array}$ & $\begin{array}{l}\text { Crearon redes } \\
\text { delegacionales } \\
\text { de comunicación, } \\
\text { dependió de } \\
\text { un organismo } \\
\text { gubernamental, } \\
\text { dio acceso } \\
\text { a servicios } \\
\text { culturales de } \\
\text { manera gratuita, } \\
\text { y redujo la } \\
\text { violencia de la } \\
\text { zona }\end{array}$ \\
\hline
\end{tabular}

Tabla 2. Taxonomías de intervenciones culturales.

Como se puede observar en la Tabla 2, se analizaron los datos obtenidos a través de una decodificación dividida en seis temas: ubicación, actividades, participantes, usuarios, duración e impacto obtenido. Estos factores asistieron a entender cómo su influencia puede variar y contribuir en la producción de diferentes resultados en participaciones sociales, que pueden convertirse subsecuentemente en iniciativas urbanas. Por ejemplo, los resultados exhiben una transición, a través del tiempo, de intervenciones públicas a privadas, e incluso el uso alterno de ambas. Otro resultado interesante, es acerca de los responsables de las intervenciones, ya que empezaron con una persona dirigiendo acciones y subsecuentemente más gente se fue uniendo a las diferentes iniciativas, hasta que un grupo pequeño se volvió central a las iniciativas. La tercera tendencia está relacionada con la duración de las diferentes iniciativas, siendo que las primeras eran breves y las últimas eran más duraderas. Estos factores permitieron divisar tres tipos de intervenciones, temporales-intermitentes, semi temporales-estables y permanentes-continuas.

Temporales -Intermitentes [intervención 1]

El primer tipo de intervención usa varios espacios para llevar a cabo diferentes tipos de prácticas que proveerán distintos lugares con una construcción y operación social única entre las personas. Estas prácticas requieren de consenso y cooperación entre miembros de la comunidad, ya que necesitan apropiarse de un lugar por un tiempo breve de manera temporal e intermitente. El espacio urbano es reclamado por los residentes que no tienen 
las capacidades para tener un espacio formal para llevar acabo su práctica. Es decir, se apropiaron de los espacios púbicos de manera ilegal por un lapso de tiempo para llevar a cabo actividades culturales, sociales y recreativas. La inclusión a las actividades es obtenida a través del descubrimiento del grupo, por invitación o por recomendación. La figura 7 exhibe como los diferentes espacios ofrecen experiencias humanas únicas debido a las diferentes prácticas llevadas a cabo. Las intervenciones en los lugares son intermitentes y su duración e intensidad es breve y continua. La participación de la comunidad se incrementa conforme las prácticas evolucionan por que se genera confianza. El efecto de la intervención es intermitente, pero tiene potencial de crecer. Para eso se requiere agencia junto con la utilización de capacidades dinámicas de conocimiento que le permitan a la comunidad asimilar, transformar y desplegar nuevas iniciativas.

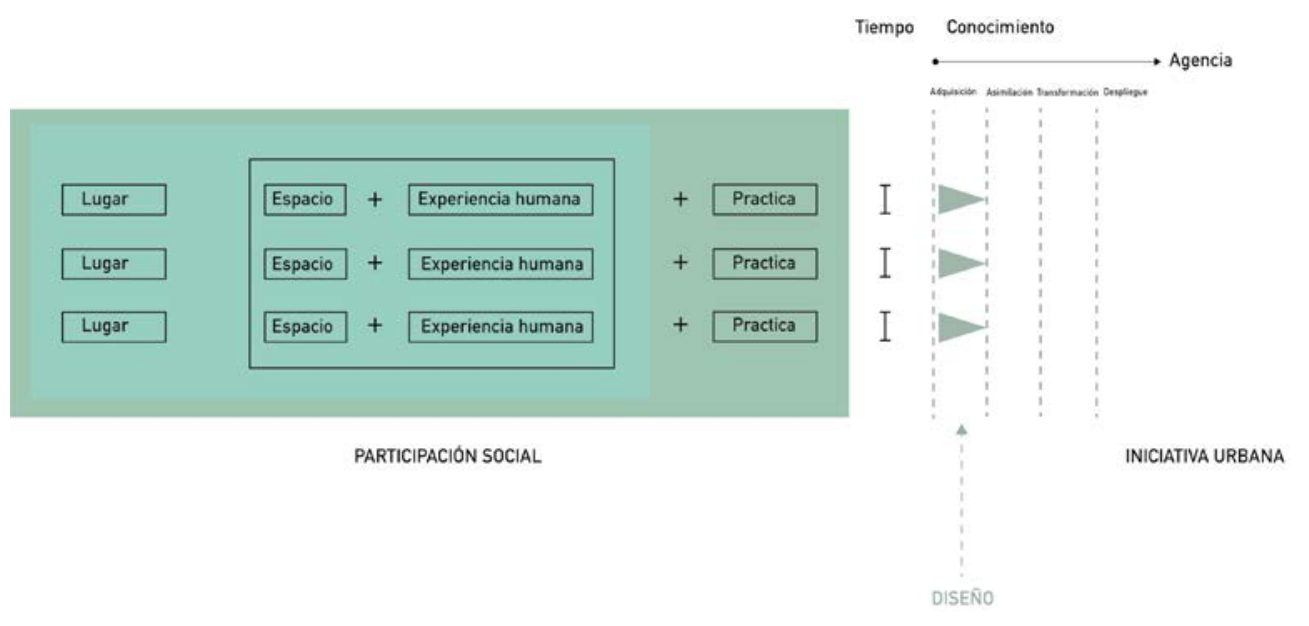

Figura 7. Temporales-Intermitentes.

El diseño puede contribuir en este tipo de intervenciones, como un agente de conocimiento que puede ayudar a las comunidades a coordinar exploraciones, visualizar posibilidades y sobre todo a catalizar las participaciones en iniciativas con agencia. Esto es esencial si se requieren consensos para intervenir espacios que lleven a mejorar la comunidad.

Semi temporales - Estables [intervención $2+3$ ]

El segundo tipo de intervención, usa varios espacios públicos y privados para llevar una práctica específica con diversas experiencias humanas. Dicha práctica se convirtió en un 
ritual que tenía un significado para los miembros de la comunidad, porque era un punto de referencia (memoria) de una serie de actividades. Los espacios se convirtieron en un lugar con valor social porque las intervenciones construían por un tiempo un espacio formal donde se llevaban actividades culturales, recreativas y sociales. La posibilidad de transformar espacios se incrementaba debido a la legitimidad aprobada por la comunidad.

La membresía a este tipo de intervenciones fue través de la participación activa en la práctica llevada en el lugar. La figura 8 expone como cada espacio ofrece una experiencia humana única que tienen como objetivo una práctica específica en un lugar. Así mismo, exhibe que las intervenciones son continuas, ofreciendo una estabilidad en la percepción de la comunidad, aun a pesar de que éstas ocurren temporalmente durante el año. La participación de la comunidad es esencial para la toma de decisiones, y por ello se involucra al mayor número posible. El efecto de la intervención es estable y por ello es legitimado por la comunidad. Debido a que la misma práctica fue llevada por un tiempo extenso, permitió a los partícipes adquirir, asimilar y transformar el conocimiento adquirido durante las intervenciones. Esto permite pasar de una simple participación social a una posible iniciativa urbana.

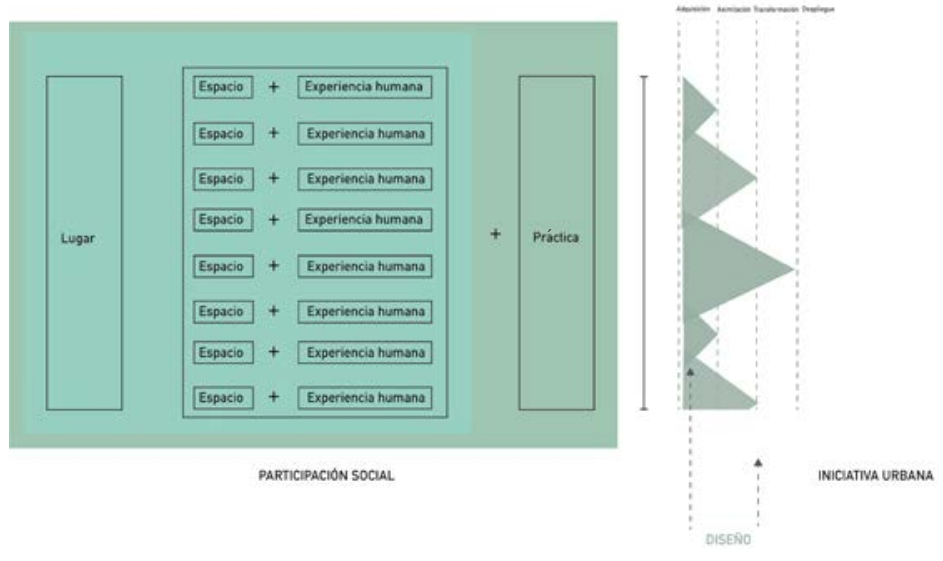

Figura 8. Semi temporales - Estables.

En este tipo de intervenciones, el diseño puede actuar como un instrumento para facilitar conocimiento, navegar en complejidades y mediar partes interesadas. Los diseñadores pueden ayudar a miembros de comunidades a entender sus actividades y cómo pueden 
INTERVENCIONES URBANAS Y TEJIDO SOCIAL

EN LA CIUDAD DE MÉXICO

aprender de ellas para mejorar su actividad. Como navegadores de complejidades pueden ayudar a entender ambigüedades, proveyendo con ello incertidumbre y riesgos en la implementación de posibles intervenciones urbanas. Finalmente, como mediadores ofrecen soluciones a múltiples grupos de personas, a menudo interesadas en diferentes perspectivas, necesidades y expectativas, permitiendo con ello tener una agencia en las intervenciones.

\section{Permanentes - Continuas [intervención $4+5+6$ ]}

El tercer tipo de intervención, se concentra en la utilización de lugares permanentes para llevar una serie de prácticas que están interconectadas a un proyecto mayor [iniciativa urbana]. Es decir, el espacio está planeado en un lugar formal que fue diseñado para propósitos específicos y por lo tanto tiene un mercado objetivo. Por ello, su administración es regulada por un grupo de personas que son reconocidas y legitimadas por la comunidad. Los usuarios no ejercen ningún poder sobre la intervención, ya que no son consultados para realizar algún cambio o modificación en el espacio. Una persona se vuelve miembro de estas intervenciones a través de dos opciones: una, pagar una cantidad de recursos financieros en un periodo de tiempo a través de una relación contractual o ser un miembro activo de la intervención. Las actividades culturales dependen en el número de usuarios que puedan costear o tengan el tiempo para participar en las actividades. La figura 9 muestra que cuando una intervención urbana se formaliza a través de la construcción de un espacio dedicado a actividades culturales, su duración e intensidad se incrementan exponencialmente. Sin embargo, una de las debilidades de este tipo de intervención es que su origen demanda una participación social activa, la cual se ve reducida y limitada con el paso del tiempo. La participación social se vuelve permanente, una iniciativa urbana, y esto lleva a que los responsables de la intervención generen valor a través de la adquisición, la asimilación, la transformación y el despliegue de conocimiento, ya que si no lo hacen están destinadas a la extinción. 


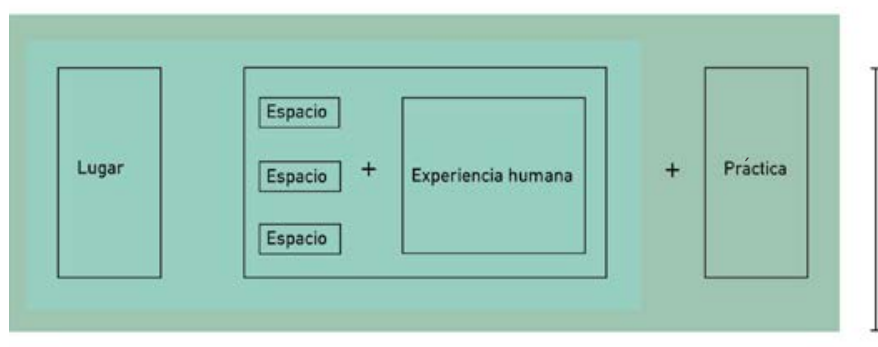

PARTICIPACIÓN SOCIAL

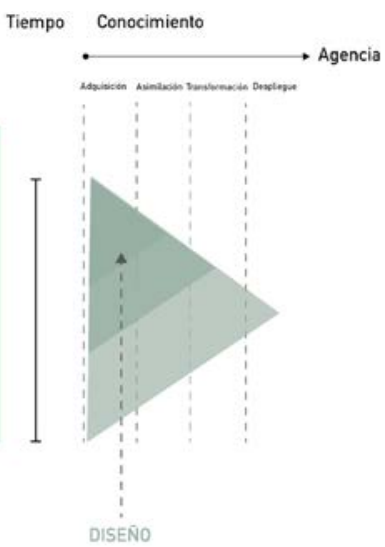

INICIATIVA URBANA
Figura 9. Permanentes - Continuas.

El diseño en este tipo de intervención se convierte en un instrumento para negociar, visualizador de lo intangible, mediador y coordinador de exploraciones. Cuando es utilizado para negociar, el diseñador tiene que tomar decisiones que ayuden a incrementar el valor financiero del negocio en una situación comercial. Como visualizadores deben ser capaces de sintetizar las posibilidades futuras, manipulando los desafíos relacionados con entidades abstractas e inteligibles. Cuando son mediadores ofrecen diferentes soluciones que requieren tomar en consideración las perspectivas, necesidades y expectativas de todas las personas interesadas en la actividad. Finalmente, como coordinadores de exploraciones deben usar recursos contextuales para maximizar la creatividad en los diferentes procesos y acciones llevadas a cabo en la iniciativa urbana.

El siguiente análisis decodificó la información obtenida de dos intervenciones considerando su tipo de taxonomía, su conocimiento y habilidades en proyectos, su entrega de servicios y su tipo de cultura laboral. La tabla 3 sintetiza los resultados obtenidos a través de la información documentada en dos intervenciones del caso longitudinal. 
INTERVENCIONES URBANAS Y TEJIDO SOCIAL

EN LA CIUDAD DE MÉXICO

\begin{tabular}{|c|c|c|}
\hline \multirow{2}{*}{ Nivel } & \multicolumn{2}{|c|}{ Condición } \\
\hline & Intervención 4 (+6) & Intervención 5 \\
\hline Organización & $\begin{array}{l}\text { Taxonomía creativa } \\
\text { Basadas en la cultura } 25 \% \\
\text { Recursos creativos intensos } 30 \% \\
\text { Proveedor cultural especializado } 15 \% \\
\text { Proveedor externo } 30 \%\end{array}$ & $\begin{array}{l}\text { Taxonomía creativa } \\
\text { Basadas en la cultura 30\% } \\
\text { Recursos creativos intensos 50\% } \\
\text { Proveedor cultural especializado } 20 \% \\
\text { Proveedor externo } 0 \%\end{array}$ \\
\hline Proyecto & $\begin{array}{l}\text { Experto } 25 \% \\
\text { Competente } 30 \% \\
\text { Aprendiz } 15 \% \\
\text { Entrante } 30 \%\end{array}$ & $\begin{array}{l}\text { Experto } 28 \% \\
\text { Competente } 18 \% \\
\text { Aprendiz } 44 \% \\
\text { Entrante } 10 \%\end{array}$ \\
\hline Servicio & $\begin{array}{l}\text { Superior } 20 \% \\
\text { Aumentado } 30 \% \\
\text { Existente (presente) } 22 \% \\
\text { Básico } 28 \%\end{array}$ & $\begin{array}{l}\text { Superior } 22 \% \\
\text { Aumentado } 35.15 \% \\
\text { Existente (presente) } 16 \% \\
\text { Básico } 26.85 \%\end{array}$ \\
\hline Cultural & $\begin{array}{l}\text { Activo } 40 \% \\
\text { Realizador } 42.9 \% \\
\text { Reactivo } 15.1 \% \\
\text { Pasivo } 2 \%\end{array}$ & $\begin{array}{l}\text { Activo } 8.6 \% \\
\text { Realizador } 42.9 \% \\
\text { Reactivo } 28.5 \% \\
\text { Pasivo } 20 \%\end{array}$ \\
\hline
\end{tabular}

Tabla 3. Condición de la intervención 4 (+6) y 5

En lo que respecta a la taxonomía cultural, la intervención $4(+6)$ invierte en recursos creativos de forma intensiva (30\%) para proveer actividades basadas en la cultura (25\%), aunque depende de proveedores externos para extender su oferta cultural (30\%). La intervención 5 invierte una gran parte de sus recursos en actividades creativas (50\%) y en actividades culturales (30\%), por lo que se está formando como un proveedor de cultura (20\%). Cuando se evaluó la competencia de habilidades en proyectos, la intervención $4(+6)$, es respaldada por 14 años de experiencia que se pueden observar en el conocimiento experto (40\%) y competente (30\%) en el desarrollo de sus proyectos. Aunque, esta sufre problemas en su monitoreo de actividades y planeación ya que sus habilidades son de aprendiz (15\%) y entrante (5\%). La intervención 5 no cuenta con experiencia relacionada a la administración de proyectos institucionalizados de cultura y su promoción (54\%). Por ello, se enfoca en la implementación y monitoreo de actividades (46\%) que les permite día a día resolver problemas con referente a su oferta de servicios. En cuanto al servicio, la intervención $4(+6)$, no tiene una estrategia enfocada en entregar un tipo específico de servicios, por ello sus 
cualidades son muy homogéneas en actividades aumentadas (20\%) y superiores (30\%) con referente a existentes (22\%) y básicas (28\%). La intervención 5 tiene un patrón similar ya que sus servicios rondan en los siguientes porcentajes, superior (22\%), aumentado (35.15\%), existente (16\%) y básico $(26.85 \%)$. Finalmente, su cultura organizacional difiere ya que los miembros de la intervención $4(+6)$ son más activos $(40 \%)$ ya que dependen de la realización de proyectos (42.4\%) para continuar siendo apoyados por organizaciones externas. Contrariamente, los miembros de la intervención 5 tiende a ser más pasivos (20\%) y reactivos (28.5\%) en la propuesta de nuevas actividades culturales ya que tienen un mercado cautivo que paga por realizar actividades de forma continua (42.9\%).

Como se puede ver, la intervención $4(+6)$ tiene desarrollo cultural basado en actividades internas soportadas por agentes culturales externos intermitentes. Sus conocimiento y habilidades en el desarrollo de proyectos son competentes ya que se han dedicado por varios años a dicha actividad. Su oferta cultura es mayor que la existente en los alrededores ya que está dirigido a grupos específicos con ciertas preferencias, intereses y habilidades. Cuentan con un grupo pequeño de personas que son activas en el desarrollo de actividades que mejoren la comunidad a través de actividades artísticas. Un factor que ayuda al éxito de esta intervención es el apoyo constante e intenso de la comunidad que participa en el proyecto. Por el contrario, la intervención 5 está dedicada a invertir de forma intensiva en la cultura. Sus proyectos han sido afectados por la falta de capacidades, habilidades y experiencias en actividades culturales en organismos culturales autónomos. Sus servicios son mejores que los existentes, pero tienen deficiencias que reducen su percepción de calidad. Por ello su cultura organizacional es más reactiva y pasiva a las condiciones actuales, pocos profesores siguen realizando actividades culturales relevantes para la comunidad. 


\section{Conclusiones}

Los habitantes de la comunidad estudiada fueron capaces de redefinir espacios-lugares de su paisaje urbano, a través de actividades culturales, sociales y recreativas enfocadas a diferentes grupos de la sociedad. Algunas de las prácticas llevadas a cabo por los miembros de la comunidad se convirtieron en un ritual al mismo tiempo que transformaron áreas públicas en puntos de referencia para la comunidad. Se encontraron tres tipos de intervención; temporal-intermitente, semi temporal-estable y permanente-continua. Dependiendo de la intervención, se ven reflejados la participación y el apoyo de la comunidad con respecto a la duración e intensidad de la misma. Las mejoras experimentadas a nivel social en la comunidad fueron: mejor relación vecinal, mayor participación vecinal y comunitaria, fortalecimiento en la relación vecinal, mejora económica en los negocios de la zona, reducción de violencia en la zona, creación de redes zonales y acceso a actividades culturales. El diseño puede ser y es utilizado de forma tácita como negociador, visualizador de lo intangible, facilitador de pensamiento, navegador de complejidad, mediador de partes interesadas y coordinador de exploraciones. Este caso requiere ser entendido desde diferentes enfoques de estudio para entender de manera detallada los símbolos, rituales y representaciones sociales disponibles públicamente que fueron llevados en un tiempo y lugar definidos. Esto permitirá explorar si es posible igualar las actividades en otras áreas. Es importante mencionar que este trabajo es descriptivo y exploratorio que tiene como objetivo entender, en un caso específico, cómo las intervenciones urbanas culturales mejoraron el tejido social de una comunidad situada en una zona marginal de la Ciudad de México. Una limitación de este trabajo es que analizó un solo caso de estudio que es aplicable a las condiciones de una locación especifica. Un mayor trabajo se necesita para establecer mejores instrumentos de investigación y determinar la relevancia del diseño en la mejora del tejido social. 


\section{Referencias}

Alexiou, K.; Johnson, J. \& Zamenopoulos, T. (2010).

Embracing Complexity in Design: Emerging Perspectives and Opportunities, in Designing for the 21st Century Interdisciplinary Methods and Findings, Tom Inns, ed., London: Gower, 87-100.

Augé, M. (1995). Non-places: Introduction to an Anthropology of supermodernity. London, England: Verso.

Aractingi, J. \& Le Pape, G. (2011). Rituals and catechisms in ecumenical rite in East and West at the crossroads masonics. Paris, France: Editions L'Harmattan.

Aravena, A. (2006). La ciudad como Fuente de Equidad. ACTAR Architecture Boogazine, 6, 160-167.

Balnaves, M. \& Caputi, P. (2001). Introduction to quantitative research methods: An investigative approach. London, England: Sage.

Bell, C. (1997). Ritual: Perspectives and dimensions. New York, New York: Oxford University Press.

Bertola, P. \& Teixeira, J. (2003). Design as a knowledge agent: How design as a knowledge process is embedded into organizations to foster innovation. Design Studies, 24(3), 181-194. doi: http://dx.doi. org/10.1016/S0142-694X(02)00036-4

Borja de Mozota, B. (2006, a). The four power of design: A value model in design management.

Design Management Review, 17(2), 44-53.

Borja de Mozota, B.(2006, b). A theoretical model for design in management science: From management as a constraint to management science as an opportunity for the design profession. Design Management Review 3(1) 2006, 11

Bruce, M.; Cooper, R., \& Vazquez, D. (1999). Effective design management for small business.

Design Studies, 20(3), 297-315. doi: 10.1016/S0142$694 X(98) 00022-2$

Bryman, A. (1989). Research methods and organization studies. London, London: Routledge.
Buchanan, R. \& Margolini, V. (1995, Eds.). Discovering Design. Illinois, Chicago: University of Chicago Press.

Candi, M. (2005). Design as an element of innovation: Evaluating design emphasis and focus in new technology-based firms. Háskólinn: Reykjavik University.

Casey, E. (1996). How to get from space to place in a fairy short stretch of time: Phenomenological prolegomena. En S. Feld \& K. Basso (Eds.), A Senses of Place (pp. 13-52). Santa Fe, New Mexico: School of American Research Press.

Certeau, M. (1990, Eds.). L'Invention du quotidian. 1 Arts de Faire. Gallimard: Folio-Essais.

CEPAL. (2007). Cohesión social. In/cusión y sentido de pertinência en América Latina y el Caribe. Santiago de Chile: CEPAL, AECID, SEGIB.

Cloke, P., Philo, C., \& Sadler, D. (1991) Approaching human geography. London, England: Sage Publications.

Coleman, P., \& Collins, S. (Eds.) Locating the Field: Space, Place and Context in Anthropology (67-86) Oxford, England: Berg.

Collins, J. \& Hussey, R. (1996). Business research: A practical guide to undergraduate and postgraduate students. Basingstoke, England: Palgrave Macmillan.

Creswell, J. (2009). Research design: Qualitative, quantitative, and mixed methods approaches (3rd ed.). London, England: Sage Publications.

Crotty, M. (1998). The foundations of social research: Meaning and perspective in the research process. London, England: Sage.

Devine-Wright, P., \& Lyons, E. (1997). Remembering Pasts and Representing Places: The Construction of National Identities in Ireland. Journal of Environmental Psychology, 17(1): 33-45, doi:10.1006/jevp.1996.0037 . 
Durkheim, E. (1997). The division of labor in society. New York, New York: Free Press.

Elkington, J. (1999). Cannibals with forks: The triple bottom line of the 21st century business. Minnesota, Minnesota: Capstone Publishing Ltd.

Entrikin, J.N. (1991). The Betweenness of Place: Towards a Geography of Modernity. Baltimore: Johns Hopkins University Press.

EUROsociAL (2016, noviembre, 15). Social Cohesion [Web log] Recuperado de: http://eurosocial-ii.eu/en/ pagina/cohesion-social

FIIAPP (2011). Putting social cohesion into public policies: Why, how, and who? Strategies for integrating social cohesion in public policies. Development CentreOECD. Paris, 20-21 January 2011.

Florida, R. (2002). The rise of the creative class: A how it's transforming work, leisure and everyday life. New York, New York: Basic Books.

Frias-Peña, J. (2005) The strategic role of industrial designers in developing innovative products in SMEs, [PhD thesis].

Gaspar-Guadarrama, A. (2012). In search for a reader city: Book clubs in Mexico City. Mexico City: Ministry of Culture, 58. En busca de una ciudad lectora Libro Clubes de la Ciudad de México.

Gobierno de Mexico (2016, Abril 15). Qué es el Laboratorio de Cohesión Social? [Web log] Recuperado de https://www.gob.mx/amexcid/ articulos/que-es-el-laboratorio-de-cohesionsocial?idiom=es

Gomm, R.; Hammersley, M., \& Foster, P. (Eds.) (2000). Case study method. London, London: Sage.

Halbwachs, M. (1950). Collective memory. New York, New York: Harper and Row Colophon Books.
Hargadon, A. \& Douglas, Y. (2001). When Innovation meet institutions: Edison and the design of the electric light. Administrative Science Quarterly, 46, 716-749. doi: 10.2307/3094872

Healy, M. \& Perry, C. (1998). Comprehensive criteria to judge validity and reliability of qualitative research within the realism paradigm. Qualitative market research: An International Journal 3(3): 118-126. doi: http://dx.doi.org/10.1108/13522750010333861

Hernández-Sampieri, R.; Fernandez-Collado, C., \& Baptista-Lucio, P. (1998). Research Methods, (2nd ed.), Mexico City, Mexico: Mcgraw-Hill.

Hesmondhalgh, D. (2002). The cultural industries. London, England: Sage.

Hirsch, E. (1995). Landscape: Between place and space. En E. Hirsch \& M. O'Hanlon (Eds.), The anthropology of landscape: Perspectives on place and space. Oxford. England: Claredon Press.

Hubbard, P., Kitchin, R., \& Valentine, G. (2004). Key thinkers on space and place. London, England: Sage.

Ingold, T. (2008). Bindings against boundaries: Entanglements of life in an open world. Environment and Planning, A 40, 1746-1810. doi: 10.1068/ a40156

Inns, T. (Eds.) (2007). Designing for the 21st century: Interdisciplinary questions and insights. Hampshire, England: Gower.

Jauhiainen, J.S. (2005). Linnageograafia. Linnad ja linnauurimus modernismist postmodernismini, Tallinn (Eesti Kunstiakadeemia).

Jorgensen, B.S., \& Stedman, R.C. (2001). Sense of Place as an Attitude: Lakeshore Owners Attitudes Toward Their Properties. Journal of Environmental Psychology, 21(3): 233-248, doi:10.1006/ jevp.2001.0226. 
Kotler, P. \& Rath, G. A. (1984). Design: A powerful but neglected strategic tool. Journal of Business Strategy, 5, 16. doi: http://dx.doi.org/10.1108/eb039054

Kostof, S. (1991). The City Shaped: urban Patterns and Meanings through History. New York: Bulfinch Press.

Laboratorio de Cohesión social a través de AMEXID (2016). ¿Qué es el Laboratorio de Cohesión Social?. Recuperado de: https://www.gob.mx/ amexcid/articulos/que-es-el-laboratorio-de-cohesionsocial?idiom=es

La Varra, G. (2003). Post it city: The other European public spaces in S. Boeri, Multiplicity. USE-Uncertain States of Europe. Milan, Italy: Skira.

Lee, J. \& Ingold, T. (2006). Fieldwork on foot: Perceiving, routing, socializing. En S., Lefebvre, H. (1991). The Production of Space. Oxford, Massachusetts: Blackwell.

Lefebvre, H. (1991). The Production of Space. Oxford, Massachusetts: Blackwell.

Lincon, Y. \& Guba, E. (1985). Naturalistic inquiry. Beverly Hills, California: Sage.

Low, S. (1994), Place Attachment in Cultural Anthropology. National Geographical Journal of India, 40(1-4): 47-61. Special Issue on 'The Spirit and Power of Place'.

Martin, D.G. (2003). 'Place-Framing' as Place-Making: Constituting a Neighborhood for Organizing and Activism. Annals of the Association of American Geographers, 93(3): 730-750, doi:10.1111/14678306.9303011 .

Massey, D. (2005). For space. London, England: Sage.

Mitleton-Kelly, Eve (2010) Identifying the multidimensional problem space \& co-creating an enabling environment. En: 1st International Workshop on Complexity and Real World Applications, Southampton, UK.
Montaner, J. (2013). Arquitectura y crítica (3rd ed.). Barcelona, Cataluña: Editorial Gustavo Gili.

Moustakas, C. (1994). Phenomenological research methods. California, California: Sage Publications.

Newman, W. (2000). Social research methods: Qualitative and quantitative approaches (4th ed.). Boston, Massachusetts: Allyn \& Bacon.

Norman, D.A. (2002). The Design of Everyday Things. New York, NY: Basic Books.

Norman, D.A. (2004). Emotional Design. New York, NY: Basic Books

Oppenheim, A. (2000). Questionnaire design, interviewing and attitude measurement. London, England: Continum.

Ottone, E. (2007). Cohesión social: Inclusión y sentido de pertenencia en América Latina y el Caribe. Santiago de Chile, Chile: Naciones Unidas.

Paasi, A. (2001). Bounded spaces in the mobile world: Deconstructing 'regional identity, Tijdschrift voor economische en sociale geografie, 93(2): 137-148, doi:10.1111/1467-9663.00190.

Pearce-Moses, R. (2005). A glossary of archival and records terminology. Illinois, Chicago: Society of American Archivists.

Pink, S. (2012). Situating everyday life: practices and places. London, England: Sage

Relph, E. (1976). Place and placelessness. London: Pion.

Rosa, S. \& Weiland (2013). Handmade Urbanism: From community initiatives to participatory models. Berlin, Germany: Jovis

Saar, M., \& Palang, H. (2009). The dimension of place meanings. Leaving Reviews in Landscape Research, 3(3): 1-24. 
Schatzki, T. (2001). Introduction: Practice theory. En T. Schatzki, K. Knorr-Cetina, \& E. Von Savigny (Eds.) The practice turn in contemporary theory. London, England: Routledge.

Schwandt, T. (2007). Dictionary of qualitative inquiry (3rd ed.). Thousand Oaks, California: Sage.

Seamon, D. \& Sowers, J. (2008). Place and placelessness, Edward Relph. En P. Hubbard, R. Kitchen, \& G. Vallentine (Eds.) Key Texts in Human Geography. London, England: Sage., 43-51

Sheringham, M. (2006). Everyday life: Theories and practices from surrealism to the present. Oxford, England: Oxford University Press.

Solá-Morales, I. (1996). Presente y futuros. La arquitectura en las ciudades. Barcelona, Cataluña: Collegi Oficial d'Arquitectes de Catalunya.

Soja, E.W. (1996), Thirdspace: Journeys to Los Angeles and Other Real-and-imagined Places. Malden, Massachusetts: Blackwell.

Tuan, Y. (1977). Space and place: The perspective of experience. Minneapolis: University of Minnesota.
Van Wijk, J (2005). The value of visualization. IEEE Visualization, 2005: 79-86.

Vorkinn, M., \& Riese, H. (2001). Environmental Concern in a Local Context: The Significance of Place Attachment. Environment and Behavior, 33(2): 249-263, doi:10.1177/00139160121972972.

World Urban Forum (2016, mayo, 22). Report of the third session of the World Urban Forum [Web log] Recuperado de: http://mirror.unhabitat.org/ downloads/docs/3406_98924_WUF3-Report.pdf

Yamamoto, M., \& Lambert, D. R. (1994). The impact of product aesthetics on the evolution of industrial products. The Journal of Product Innovation Management, 11(4): 309-324. doi: 0.1016/07376782(94)90086-8

Yin, R. (1994). Case study research design and methods (2nd ed.). London, England: Sage Publication. 